\title{
The status-power arena: a comprehensive agent-based model of social status dynamics and gender in groups of children
}

\author{
Gert Jan Hofstede ${ }^{1} \cdot$ Jillian Student $^{2} \cdot$ Mark R. Kramer $^{1}$
}

Received: 4 August 2017 / Accepted: 27 December 2017

(C) The Author(s) 2018. This article is an open access publication

\begin{abstract}
Despite the urgency of this issue, AI still struggles to represent social life. This article presents a comprehensive agent-based model that investigates status-power dynamics in groups. Kemper's sociological status-power theory of social relationships, and a literature review on school children in middle youth, is its basis. The model allows us to investigate causation of the near-ubiquitous phenomenon that females have lower social status on average than males. Possible causes included in the model are children's dispositional traits (kindness, beauty, and physical power), schoolyard culture (social acceptability of fighting), behavioural strategy (amount of rough-and-tumble play) and the balance between public and dyadic sources of status. An agent-based model of a virtual schoolyard was created in which the children assemble in changing groups and mutually confer status. The status conferred upon a child modifies the status it holds. Rough-and-tumble is modelled as ambiguous: it is intended as a status conferral, but may be perceived as a power move. Running many trials of the model we found that in time, depending on the parameter settings, a gender-based status gap emerged. Rough-and-tumble play had more impact on emergent status differences than did physical power differences. Social acceptability of fighting also strongly moderated the resulting status gap. Placing more weight on dyadic relationship could alleviate status loss. All these model behaviours are in line with empirical findings of child behaviour studies at schools. They have face validity for social status issues in the adult world. We conclude from this that this kind of agent-based model merits use in studying the status-power dynamics of other issues in child behaviour, or indeed in social behaviour in general.
\end{abstract}

Keywords Agent based model $\cdot$ Status-power dynamics $\cdot$ Gender gap $\cdot$ Culture $\cdot$ Rough-and-tumble $\cdot$ Sociology

\section{Introduction: status-power theory and the gender status gap}

The article is inspired by Kemper's status-power theory of social relations (Kemper 2011). This theory holds that "the inspection of any sociological problem should address as systematically as possible the relational standing of the

Gert Jan Hofstede

gertjan.hofstede@wur.nl

Jillian Student

jillian.student@wur.nl

Mark R. Kramer

mark.kramer@wur.nl

1 Information Technology Group, Wageningen University, P.O. Box 8130, 6700 EW Wageningen, The Netherlands

2 Environmental Policy and Environmental Systems Analysis Groups, Wageningen University, P.O. Box 8130, 6700 EW Wageningen, The Netherlands actors vis-à-vis each other in status and power terms" (p. 1). Our aim is to construct an agent-based model that captures the main elements of Kemper's theory. We try to keep the model as generic as possible. As our first case for implementing this theory in an agent-based model, we take a robust finding across societies: the fact that females tend to have, on average, lower social status than males (Maccoby 2002; Ridgeway 2011). We concentrate on children in middle youth, whose social behaviours are well-studied and tend to be more transparent than those of adults. We model a school playground, as an environment that allows for free, unconstrained social interaction.

Among adults, gender-related status differences are visible in disparities in relative pay per job type and number of women in positions of power (United-Nations-DevelopmentProgramme 2015). In everyday interaction, it manifests itself in subtle differences in non-verbal behaviour (Major 1981). An important contribution to gender difference comes from assumptions about the proper relative positions of men and 
women. Ridgeway shows how such assumptions can come about: "Status inequalities, then, are based on cultural presumptions about the traits of people in some social categories compared with others rather than directly on the nature of the positions they occupy in society. Since gender is a categorical distinction based on cultural assumptions about differences between people in one sex category compared with the other, it is at root a status inequality" (Ridgeway 2011, p. 11). In this article we shall call it the 'gender status gap'.

\section{Nature versus nurture}

So what pathways lead from sex traits, gendered beliefs, and behavioural tendencies to a status gap between the sexes?

In folk psychology, these differences are frequently attributed to differences in physical power, though frequency distributions of physical power for girls and boys overlap strongly (Eliot 2009). In almost all properties, differences between the sexes are smaller than differences within the sexes (Campbell and Eaton 1999; Eliot 2009). The alleged weakness of women has been nicknamed the 'frailty myth' (Dowling 2000). So is it all nurture?

Nurture is certainly powerful. Eliot (ibid.), and many others, identified strong socialisation forces right from birth (Haviland and Malatesta 1981; Kang and Inzlicht 2012; Malatesta and Haviland 1982). Infants adapt their display rules to such overpowering feedback. Boys obtain no status from whimpering, and avert their eyes or become angry instead-it works better. For girls, anger costs them status with their parents and crying earns them status. Mothers' retrospective reports (Tremblay et al. 1999) as well as longitudinal research (Baillargeon et al. 2007) show that the steepest increase in boys' aggressive behaviours occurs between 11 and 15-17 months. This is an age at which they recognise their parents, other familiar faces and strangers, while there is no testosterone boost compared to girls. We can speculate that little boys and girls receive strong socialisation during this time that mediates this gendered development.

\section{Structure, process, action}

Another conceptual distinction with a history of controversy is structure versus process. The concept of gender status gap is a structural one. Here we want to study its causation, and for that we need processes of social interaction. We assume that the two are mutually constituent of one another. People both observe and change the social world. They can choose whom to interact with and what actions to engage in. There could be gender-related strategies of action. Without necessarily being conscious of it, these action choices could contribute to changing or perpetuating social structure, including the gender status gap.

\section{Children as study object}

Gender-linked status assumptions are part of children's socialisation (Shutts 2015). By age six, children are firmly socialised into their gender and culture (Baron 2015). They likely reinforce their parent's and other older people's socialisation through peer socialisation (Rose and Rudolph 2006). The child development literature abounds with hypotheses on pathways by which empirically observed patterns are caused. With this work, we offer an addition to the methods toolkit for studying causation of such patterns. We focus on children in middle youth, between age 7 and puberty. These are old enough to have full-fledged social lives and young enough to be comparatively free from myriad constraints and complications on these social lives. Such complications include puberty, financial interests and formal positions of relative power. In many countries they enjoy playtime in same-age mixed-sex groups in playgrounds, with limited adult supervision. They have been well-studied and gendered patterns have been found in many ethnographies and experimental studies of children playing (Eliot 2009; Thorne 1993; Woods 2013). We investigate children playing in a mixed-sex playground, as a possible arena where gendered patterns are taught, learned and reinforced. The playground context allows for free socialising and the emergence of social patterns.

\section{Article structure}

We first discuss the theory necessary to design the agentbased model (ABM). We use Kemper's status-power theory of social relations as a comprehensive theory to motivate the artificial children. For social endorsement of fighting or the lack thereof, we discuss Hofstede's work on national culture. To predict system-level patterns that might emerge on the artificial playground, studies of child behaviour are reviewed. We mention previous similar studies, of which there are few. Then, the model and its operation are presented. We discuss the results in terms of the patterns expected based on the literature and hypothesise about policy implications for schools. Finally, we make some remarks about the potential of this kind of model for modelling social behaviour more generically. 


\section{Social interaction: status-power theory}

\subsection{Are tasks needed?}

The literature on status in sociological social psychology is largely based on task-based groups. For that reason we shall first discuss whether tasks are required when modelling social behaviour. In such cultures, having a task to perform is considered a good reason to form a group, and finishing the task is a ground for dismantling that group. In less individualistic countries, groups tend to be more permanent and less focused on a particular task (Hofstede et al. 2010).

Even in task-based groups the importance of the task could be overemphasized. Status-relevant attributes such as gender that might be technically irrelevant for the task at hand turn out to predict attempts at performing that task (Martin 2009). Apparently, the 'ability to make contributions' is by no means a straightforward issue. It is subject to barriers, socialisation, and prejudice. This is not the place for an extensive review. Many books have been written on the subject of what we could call socially constructed competence that provide abundant evidence of similar situations, including some of the literature cited in the introduction.

We conclude that it is worthwhile creating a model without tasks; tasks can be added in subsequent versions. For now, we focus on social interaction without any predefined instrumental aim. We assume that a school playground with children represents such interaction. The children cannot leave the grounds, but they are free to assemble with whomever they like and to engage in whatever activity they wish.

\subsection{Status as social importance}

As a theory of social motivation, we adopt sociological status-power theory of social relations for its comprehensiveness (Kemper 2011). It applies not to particular kinds of groups or contexts, but to all people anywhere. Kemper (p. 13) explains the essence of his theory as follows: "Relational activity occurs in two main forms that are distinguished by where actors stand with respect to their compliance with the wants, needs and interests of other actors. Either one can comply voluntarily or one can be coerced into involuntary compliance. The former broadly covers what I call status and the latter power."

We need to spend some time explaining the word "status'. Kemper (p. 13): "In this work, I use the term status in two ways, both of which conform to prior sociological usage (...). The first usage is scalar and refers to the rank or standing in amount of worth or prestige or other designation of merit and value that attaches to a person or social position in a group". Kemper continues (p. 14): "with respect to the second meaning of status, to say that a person's status or rank is high or low is to signify something about what people actually do when they are being voluntarily compliant (...). Thus, we define status also as the actual acts or means by which the scalar standing, worth, prestige, honour of a person or social position is conveyed in interaction".

\subsection{Status is public}

Status in the scalar sense is a public attribute at group level. By according status we confer 'social importance' on others (Mascarenhas et al. 2013). This social importance conferred, when observed by third parties, signifies that status receivers must be worthy of the status conferred, and thus sets the standard for future status exchanges. As a result, status conferrals lead to emergent status landscapes in groups and societies.

\subsection{Status worthiness}

So in fact it is not pecking order, but status worthiness that is the central concept in Kemper's work. In this, his theory resembles the moral virtue theory of status attainment (Bai 2016). Bai proposes that beyond dominance and competence, moral virtue garners admiration from others. Kemper's work is more general, since the source of statusworthiness does not need to be moral, but could be anything at all. One could for instance show worthiness at first sight through beauty, in a task context through skill, in social action through kindness, in fights through power, or in any group context through the status conferrals that others make to one, revealing previously acquired social status. Consistently showing status-worthy traits and behaviours can add up to a social history that provides a high scalar status.

\subsection{Claiming status}

People also try to obtain voluntary status conferrals by showing status worthiness. Kemper call this "claiming status'. He asserts (p. 37): “...we may treat it as axiomatic, that status-seeking is a perpetual aspect of relational interaction." For example, we claim status by showing off, looking at someone, cracking a joke, or claiming the ball. We claim status as group members by standing next to a group, e.g., at a cocktail party. Especially in new groups, mutual claiming of status happens frequently. 


\subsection{Status deficit}

If our claims and the conferrals we receive are not commensurate, we keenly perceive this, even in little ways. We feel pleased or honoured if we receive more status than we claim, for instance if someone says "you look good today!". We feel snubbed or insulted if we receive less, for instance, if we greet someone and they do not greet back. Loss of status weighs heavier than status gain; we are dismayed at status loss or deprivation more than we seek and are gratified by status gain (Kemper, p. 18).

\subsection{Power}

We now turn to the other side of Kemper's coin, power. Kemper (p. 21): "Over the long run, it is consistently the case that the sum of all human status claims, either individually or in the aggregate, is not matched by the sum of all status conferred, the former exceeding the latter. In light of this discrepancy, power enters social relations." Kemper's concept of power refers to what is done against someone's will, and is normally called coercion, force, or aggression. People start using power when they deem the status conferred by others is below expectations. In such cases, one feels resentment. Power emerges as a fall-back option for obtaining status conferrals. It has both a structural and a behavioural aspect, just like status.

Fighting offers a quick fix for obtaining status accord, but it tends to come at a price in the long run. This is moderated by social endorsement of fighting by third parties. Bystanders may accord status to the winner, because they believe winning demonstrates deservingness. Losers of fights are unlikely to willingly accord status to winners, which means that their accord of benefits is coerced and thus will be accompanied by reluctance or resentment. A loser might opt for admiring the winner instead and derive status from having been in a fight with such a deserving opponent.

\subsection{Ambiguity of status and power}

There is considerable ambiguity in social life about status and power. Kemper (p. 28): "Given even a modest appreciation of the dynamics of status and power behaviour, it should be apparent that status- conferral is not always what it seems". We often confer status strategically because we seek conferrals of status from others, or because we fear their power. From the other side of a relation, we disguise power moves as status conferrals. We might, for example, disguise an order as a request, or a crunching squeeze as a handshake.

A case in point with relevance for our playground is rough-and-tumble play (R\&T). This consists of according status to somebody by playing with them, while at the same time using one's power against the other person. It gives the message "you'd better confer status back on me, or else I could force you to do so". The other person can accept and engage in a bout of mutual play, probably making both feel good, or refuse and risk that the rough-and-tumble degenerates into aggression. Rough-and-tumble play is part of our basic repertoire as humans. The term rough-and-tumble was first used for rhesus monkeys but gained acceptance for describing humans (Humphreys and Smith 1987; Jarvis 2007). We shall have more to say about rough-and-tumble when discussing child research.

A summary of status-power theory as a basis for ABM with more examples and relations with culture can be found in G. J. Hofstede, Dignum, Prada, Student, and Vanhée (2015).

\subsection{Child behaviour studies and status-power theory}

Status-power theory posits that one can show status worthiness, which is the basis for obtaining status, in many ways. To simplify, there are three main roads to achieving status:

- 'beauty': attracting voluntary conferrals of status,

- 'kindness': conferring status on others,

- 'power': attracting coerced conferrals of status.

We shall take these three roads as a working hypothesis for traits and behaviours to provide our modelled children with. With them in mind we investigate the literature.

\subsection{Beauty, kindness and power}

Beauty, in the form of socio-economic status or physical attractiveness, was found to be a precursor of perceived popularity (Cillessen and Mayeux 2004; Gifford-Smith and Brownell 2003; Rodkin et al. 2000).

Kindness, often called pro-sociality, is associated with other children's social preference for the kind child. It is found to be higher on average among girls than boys, with large variance between individuals (Crick 1996; Eliot 2009; Ellis and Zarbatany 2007; Lansu et al. 2013; Rose and Rudolph 2006; Warden and Mackinnon 2003; ZimmerGembeck et al. 2005).

Exercising power is commonly referred to as aggression. Boys are more aggressive overall (Rose and Rudolph 2006). Girls tend to use relational aggression and boys physical (Parke and Slaby 1983; Pellegrini and Smith 1998; Warden and Mackinnon 2003), though these two forms are highly correlated at the individual level (Cillessen and Mayeux 2004).

A longitudinal study among preadolescents in the American Mid-West found three concepts to have social meaning: prosocial behaviour, likeability, and social impact 
(Zimmer-Gembeck et al. 2005). These concepts can be translated as a tendency to confer status (pro-sociality, 'kindness'), a tendency to attract status conferrals (likeability, 'beauty'), and the social status resulting from past behaviours (social impact, 'status').

We conclude that the literature provides support for the assumption that the children can observe one another's beauty, kindness, power, and status. It also provides support for our use of only these variables-apart from sex-as child attributes.

\subsection{Rough-and play}

In status-power terms, rough-and-tumble play amounts to using power as a means to simultaneously assert statusworthiness and friendship (Humphreys and Smith 1987). These authors labelled the following behaviours as R\&T: teasing, hitting and kicking, poking, pouncing, sneaking up, carrying other children, play fighting, piling on each other, charging, holding, and pushing. R\&T is much more prevalent in boys than girls and peaks in early adolescence (DiPietro 1981; Humphreys and Smith 1987; Rose and Rudolph 2006). Pellegrini found that "generally, for popular children rough-and-tumble play is positively correlated with social problem solving" (Pellegrini 1988, p. 804). A review of 30 years of research found that R\&T occurs among children with relatively similar status, and seems to help establish a dominance hierarchy defined as a 'dyadic, affiliative relationship' (Pellegrini and Smith 1998). Children tend to initiate it with others of slightly lower status than their own. Incidentally, status similarity in partner selection was also found for dominance interactions among children in summer camps (Martin 2009). For popular children, R\&T tends to lead to games-with-rules. It is always in danger of escalating into unalloyed power use, particularly for unpopular children who are less able to use R\&T to their social advantage. Such unpopular children might then fall victim to bullying practices. Bullying constitutes systematic aggression. A study in Colorado on bullying at three different ages found that it was intricately connected to social status (Guerra et al. 2011). Across all ages and both sexes, children with low self-esteem were more likely bullied: "the weak get picked on" (Guerra et al. 2011, p. 305). Studies in Scotland and the Netherlands found that boys could derive social status from bullying, whereas girls were penalised (Lansu et al. 2013; Warden and Mackinnon 2003).

$\mathrm{R} \& \mathrm{~T}$ is inherently ambiguous. Boys are more likely to initiate R\&T and to appreciate it than girls. Woods, in an ethnographic study in a London school, shows that misunderstandings are likely: boys may claim friendly intent whereas girls may claim they are being attacked (Woods 2013). For our model we only implement R\&T. Our line of reasoning is that if receivers refuse status conferrals that are accompanied by R\&T, they will consider that they are being bullied.

\subsection{Gender status gap}

If we have a formal measure for status in a group, we can define the 'gender status gap' as the difference between the average status for boys and the average status for girls. Gender status measures can be obtained in society by proxies such as salary, and directly in our proposed model.

At classroom level, the gender status gap can vary. One study among same-age groups in North-eastern USA found girls to be on average both better liked and more popular than boys during adolescence, though by small margins (Cillessen and Mayeux 2004). This does not necessarily mean that girls have the upper hand. The study also found that aggressive children, especially boys, formed cohesive groups. If they systematically accept R\&T from one another, these boy members would confer a lot of status upon one another. Such a mechanism might cause popular boys to have higher status than girls even though girls had more status on average, provided enough other boys were dropouts. Popular boys' 'collective dominance' could increase with age, as adult supervision decreases.

\subsection{Culture and the gender status gap}

'Culture' as a concept is used in many ways. We take Hofstede's informal definition "the unwritten rules of the social game" (Hofstede et al. 2010). Thus, culture is an attribute of the social system, shared by its members.

At society level, acceptability of power use as a way of getting what one wants emerged as one of the six big issues of social life (Hofstede et al. 2010). This work defines culture as the 'software of the mind' that modifies status-power logic. In terms of Kemper's model, culture is about the shared unwritten rules that specify what claims, conferrals and levels of power use are considered normal, by whom, and in what context (G. J. Hofstede 2013).

This article therefore focuses on the culture dimension of 'masculinity' versus 'femininity'. This dimension draws a continuum of the relative preference for power use: 'stand up and fight' versus 'sit down and talk'. In 'masculine' cultures, 'male prerogative' exists, and more power use is expected from men than from women. Punishment is exerted through force. In 'feminine' societies, both sexes are socialised to avoid power use to gain status. This is the only dimension that shows a marked difference between Scandinavian and Anglo countries, which are otherwise culturally rather similar (Table 1). It correlates with UNDP's Gender Inequality Index. It could therefore help in elucidating different gender patterns empirically found on playgrounds in countries with different cultures. In the masculine US culture, mixed-sex 
Table 1 cultural masculinity scores (MAS; $0=$ feminine $\ldots$ 100=masculine) and gender inequality index values 2013 (GII; $0=$ egalitarian $\ldots$ $100=$ male-dominated) for selected countries (Hofstede et al. 2010; United-Nations-Development-Programme 2015)

\begin{tabular}{llllll}
\hline Feminine countries & & & & Masculine countries & \\
\cline { 5 - 6 } & MAS score & GII 2014 & & MAS score & GII 2013 \\
\hline Sweden & 5 & 6 & Canada & 52 & 25 \\
Norway & 8 & 9 & Australia & 61 & 62 \\
Netherlands & 14 & 7 & USA & 65 & 39 \\
Denmark & 16 & 4 & United Kingdom & 66 & \\
\hline
\end{tabular}

games were found not to last and to be frequently disrupted by boys (Thorne 1993, pp. 67-68), while in the feminine Swedish culture, the sexes accommodated each other, and mixed-sex games were as stable as single-sex games (Evaldsson 2003).

\subsection{Culture and playgrounds}

Empirical cross-country comparisons of power versus status use on playgrounds are rare. One American study on 'social pretend play', with part Anglo and part South Korean-American 7-year-olds, provides supporting evidence (Farver and Shin 1997). South Korea has a MAS score of 39 and a GII 2014 of 23, both considerably lower than the USA. The study found that "Anglo-American children (...) rejected their playmates' suggestions, and used directives, whereas Korean-American children described their playmates' actions and used (...) statements of agreement, and polite requests" (ibid., p. 544). These Anglo-American children's behaviours constitute power moves, while those of KoreanAmerican children are status conferrals. Other differences in social and emotional parameters are reliably found in cross-cultural samples (Cole et al. 2002; French et al. 2011; Martínez-Lozano 2011; Turiel and Wainryb 2000).

Finding that girls engage more in relational as opposed to physical aggression also appears in cross-cultural studies (Crick 1996; Zimmer-Gembeck et al. 2005). A study among US American and Indonesian children found that girls in both countries perceived more relational aggression than boys (French et al. 2002).

In some studies, children self-report that differences in strength cause the gender status gap (Guerra et al. 2011; Woods 2013). This brings to mind the 'frailty myth' discussed earlier. It could be a socially constructed phenomenon correlated with cultural masculinity. Avoiding losing to a girl is symbolically important to boys in Anglo societies (Eliot 2009).

Of course schools in one country could differ. In a study among schools, normative beliefs endorsing bullying were strong predictors of bullying incidences; this points to a possible school effect (Guerra et al. 2011).
The empirical evidence, though scarce, confirms that it makes sense to include a cultural parameter regarding tolerance for power use.

\subsection{Ingredients for our model}

We have attempted a KIDS style of modelling (Moss and Edmonds 2005): keep it descriptive. The model is described in detail in a later section. Here we present some translations from the theories introduced in the foregoing that may not be obvious without using the technical language of the model.

\subsubsection{Three sources of status}

The paragraphs that follow give the three sources of status that operate together during status conferrals. They operate at the level of the individual, the dyad, and the classroom. This division in three levels is not explicitly based on Kemper or any of the empirical work. It is based on our design intuition. Agent-based models require their agents' drives and actions to be built from the ground up. This includes mediating between theoretical abstractions and agent actions. Our solution is to work with these three levels. Their relative weight can be varied so that either of them can be made more prominent as a source of scalar status.

\subsubsection{Status-power basics: children's traits}

The children have fixed traits relevant from a status-power perspective: beauty, kindness, and power. They have a variable status that emerges from past conferrals.

\subsubsection{Dyadic relationship: has-been-nice}

The history of past conferrals by someone is one of the ingredients of the status worthiness of that person. The children in our model have dyadic relationships that form a memory of past interactions. These 'has-been-nice' relationships are used when they look for children to join after leaving a group, and when they consider doing R\&T. 


\subsubsection{Culture: fight-tolerance}

We model a single primary school class (shortened to "classroom") without specifying the source of culture. Thus, we do not need to know to what extent the classroom's culture is embedded in a school culture or a societal culture. Most importantly, for this first simulation we limit ourselves to one aspect of culture, believed to be associated with the masculinity-femininity dimension of culture. This is the social acceptability of fighting, fighttolerance. This could be associated with unconscious values and/ or with normative beliefs.

In our model, fights are won by more powerful children, modified by the size of the status deficit felt by the offended child. Fight-tolerance (FTol) is modelled as the classroom-level probability that a group condones fighting. The assumption is that in societies with low FTol, authoritative persons (parents and caregivers) will almost always blame those picking fights. Children by age ten will have found this out through experience. They will reproduce culturally dominant attitudes towards fighting. In the simulation, if a group has low fight-tolerance, a-children who pick fights will lose status, even if they win these fights. If the group has high fight-tolerance, winning tends to provide added status to strong a-children.

A few other parameters could also be varied modelwide. First, the differential use of force between the sexes is modelled through differential use of, and preference for, R\&T. Second, we experimented with giving dyadic relationship greater weight compared with status. Third, we included a 'gender prejudice factor', sex-factor-onconferral, that adds the existing GSG to all conferrals.

\subsubsection{Rough-and-tumble}

In our model, all three sources of status are used for operationalising R\&T: binary friendship, public social status, and the personal trait of physical power. $R \& T$ is initiated between friends, that is, children will do it to others they like. R\&T givers intend to confer status on friends with slightly lower status than themselves. The maximum amount of R\&T depends on the giver's power. If the receiver accepts, this increases the status conferral. The receiver will gain status and have a friendly memory of the giver. However, receivers may take offence at the R\&T, interpreting it as intimidation. In that case the receiver interprets the conferral as lower and is likely to pick a fight. The fight's outcome and social approval of the fight-picker then determine the status consequences of the R\&T for both parties.

\subsubsection{Emergent gender patterns to expect from the model}

We now return to the empirical literature on child behaviour to find social patterns, most of them obvious to many readers, that our model should reproduce. Unless otherwise specified, we expect them both at gender level and at individual level. The analysis focuses on gender effects at classroom level through the gender status gap (GSG). The GSG is calculated as the difference in the average status of boys and girls.

Pattern 1 beauty comes to correlate with status for any set of parameter settings.

Pattern 2 the status effect of kindness inversely correlates with fight-tolerance: being kind only gives status in a fightaverse culture.

Pattern 3 as an exception to pattern 2, in fight-tolerant cultures, weak children (i.e., lower power than most others) can avoid status loss if they are kinder.

Pattern 4 the status effect of power is mediated by fighttolerance; in a fight-averse group, power is irrelevant while in a fight-tolerant group it is the main source of status.

Pattern 5 in groups where boys do more R\&T than girls, they will gain status in terms of gender status gap (GSG).

Pattern 6 if children (mostly girls) place greater weight on relationship relative to status and personality, they can offset status loss through R\&T.

Pattern 7 in a fight-tolerant culture, R\&T penalises its users (mostly a-boys) if many receivers (of both sexes) take offence to R\&T.

\subsection{Related work}

We found no other agent-based models of child behaviour. In the sociological literature on status, some work is beginning to appear. For instance Grow et al. created an agentbased model of status construction in task focused groups (Grow et al. 2015). They find that behavioural principles known to spontaneously create hierarchical differentiation between individual group members also tend to align these hierarchies with categorical differences and thereby facilitate the emergence of status beliefs. This is reminiscent of the 'beauty' of our agents, and also of gender-based prejudice. Heise (2013) created an agent-based model based on affect control theory, a theory similar to Kemper's, but specifically focused on small group interactions. The theory posits that people in a meeting attempt to maintain 'affective meanings'-in our terms, to preserve their social importance, or their status. Heise's model was able to reproduce speaking time in American Jury meetings accurately. Manzo and Baldassarri (2014) created an agent-based model of deference exchange, in which agents pursue 'social influence' in no particular context, but also 'reciprocation in deferential gestures'. This reminds us of a status conferral in our model 
and the response of the agent receiving the conferral. Their agents have a 'quality' very like our 'beauty' that forms the basis for deference. They investigate status homophily in interactions, finding that in combination with agent heterogeneity, it increases plausibility of patterns generated. This reminds of the status homophily we implemented on target choice for R\&T.

\section{Method}

The model was programmed in Netlogo (Wilensky 1999). It is available on OpenABM. Documentation on OpenABM includes a model specification using the ODD protocol (Grimm et al. 2013; Müller et al. 2013). Here, only the overview is presented.

\subsection{Model overview}

The artificial children (a-children, a-girls, and a-boys) are girls and boys in middle youth on a square, undifferentiated field (Fig. 1).

Time runs in 'ticks' representing split seconds to a few seconds. Our simulation normally runs for 300 time units (about one school recess period). A-children spend each tick

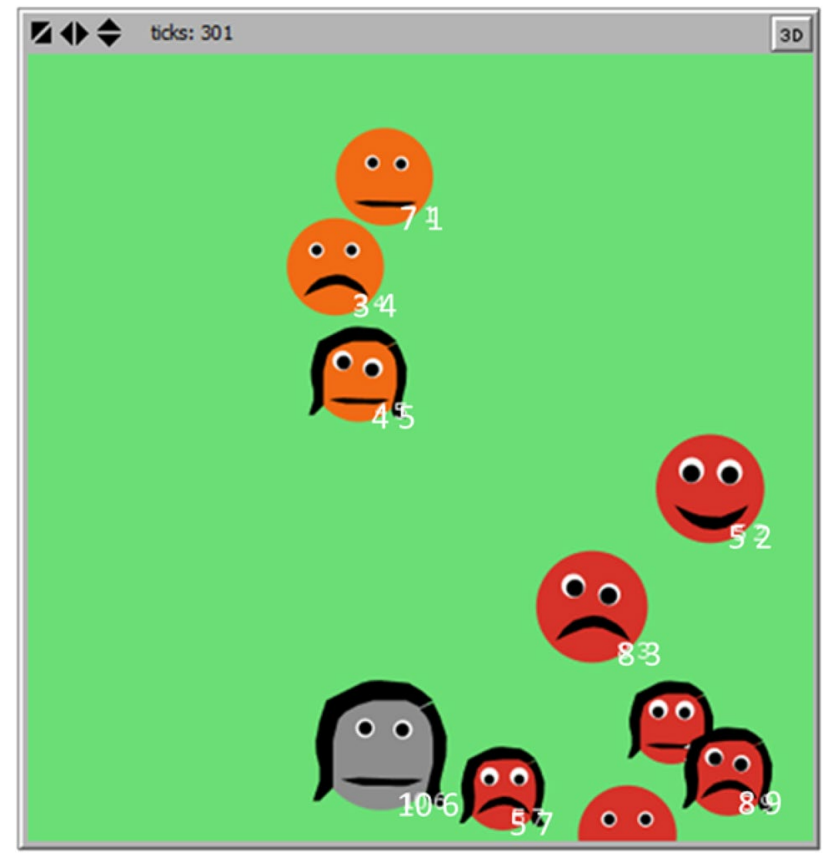

Fig. 1 Playground with 10 a-children. Colour identifies the child's group. The figure shows a group of three a-children at the top, a group of six bottom right, and a single a-girl mid bottom (a-girl 6: the rightmost number identifies the a-child). Attributes are shown as follows: sex as hair, beauty as three eye shapes, kindness as three mouth shapes, power as the leftmost number (range 0-10), and status as the a-child's size

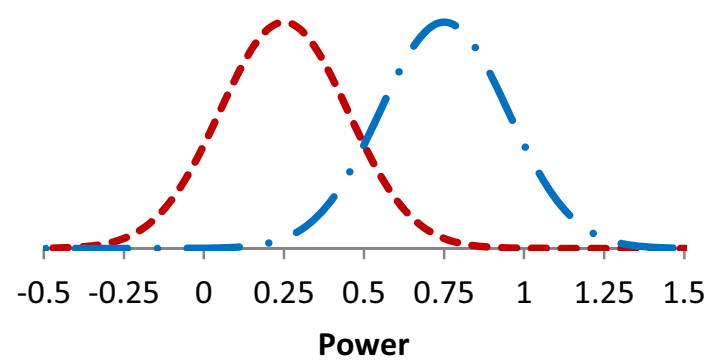

$$
\begin{aligned}
& \text { - Frequency (girls) } \\
& \text { - Frequency (boys) }
\end{aligned}
$$

Fig. 2 Distribution frequencies of power at GPR $=0.25$. This is similar to the bell curves for adult heights (Eliot 2009, p. 12). In the model, values beyond the $0-1$ interval are set to 0 and 1 respectively

forming or joining groups, making status conferrals in dyads within those groups, and perhaps fighting and/or leaving their group. Status conferrals could represent anything from a fleeting glance to passing the ball; these differences in how status is conferred are not modelled. An a-child's status is observed by all other a-children. The main dependent variable is gender-status-gap (GSG), calculated as the difference in the average status of boys and girls in the present tick. Its value can range from -1 (all girls have maximum status, all boys have minimal status) to +1 (all boys have maximum status, all girls have minimum status). Values tend to range between -0.2 and +0.2 .

Pseudo-random numbers are used for creating unique a-children (Fig. 2), as well as for introducing randomness in the status conferrals. Many runs can thus be done with the same classroom of a-children (i.e., the same initial population), but with different system parameters.

\subsection{Parameters, a-child traits and variables}

Table 2 shows all parameters. Not all are discussed in the paper; see the ODD for this. Here we mention the main variables in relation to the theory and expected patterns.

Static a-child variables (normally distributed according to a pre-set ratio G...R):

Beauty: girl-beauty ratio (GBR).

Kindness: girl-kindness ratio (GKR).

Power: girl-power ratio (GPR)

Dynamic a-child variables:

- Status: history of conferrals made to the a-child, discounted by the latest conferral. Update function: status $_{\text {new }}$ $=$ status $_{\text {old }} \times(1-$ volatility $)+$ conferral $\times$ volatility $)$. Scale $0-1$; initially 0.5 for all a-children. 
Fig. 3 Flowchart of a-child's actions during one tick

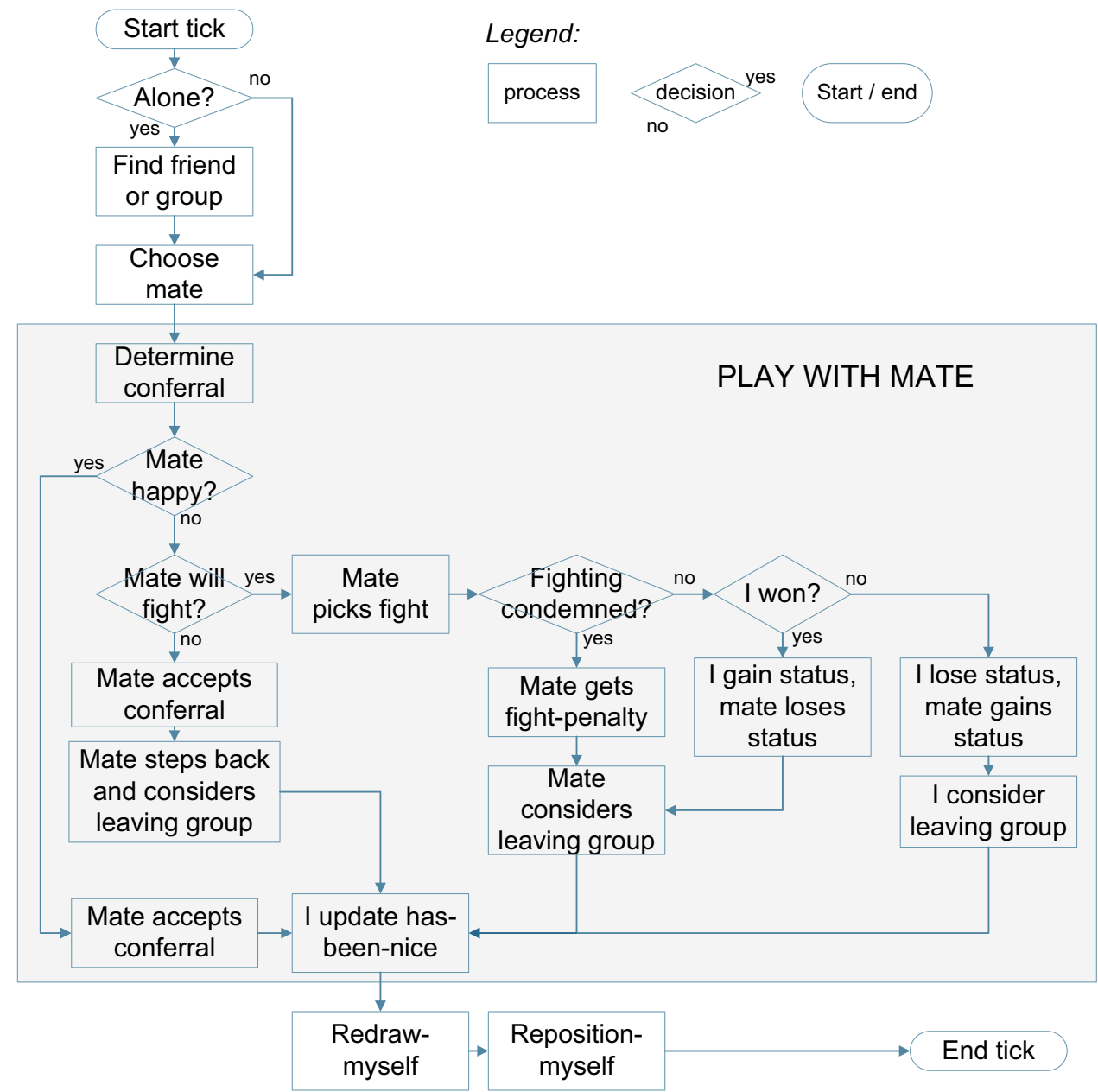

- Relationship: private 'friendship vector', a relational history of status conferrals made by others to an a-child. It captures how satisfactory conferrals have been. The variable is called has-been-nice (hbn). Scale: $-1-1$. Initialised at 0 and updated by receiving a-children after each exchange. Each a-child has a vector has-been-nice ${ }_{1 \ldots n-1}$ for all others.

Update function: $\mathrm{hbn}_{\text {new }}=\left(\mathrm{hbn}_{\text {old }} \times(1-\right.$ volatility $\left.)\right)+$ $\left(\right.$ volatility $\times\left(\right.$ status $_{\text {conferred }}-$ status $\left.\left._{\text {initial }}\right)\right)$.

\subsection{Process details}

- A-children enter the playground alone in tick 1 and go to a random patch.

- Every a-child looks for a group by trying to join the a-child it finds most attractive within its calling-distance (Fig. 3). This other a-child may or may not be alone and may or may not grant the request. An a-child can remain in its current group, create a group, or join one. A group has its own colour for as long as it exists.
- Then, within groups, a-children form momentary pairs of playmates. The playmate is not necessarily the child that granted access to the group. One playmate confers a status value on the other, and the receiver of the conferral responds. In the next tick, there will be a new and possibly different playmate.

- If an a-child receives a conferral below its expectation it may pick a fight. A fight will result in loss of status for either the loser, or, if the group condemns the fight, the fight-picker. Either a-child could be motivated to leave the group.

\subsection{Rough-and process}

The simulation can be run with or without R\&T. With $\mathrm{R} \& \mathrm{~T}$, each conferral may be topped up with a R\&T-value (see Fig. 4). 
Table 2 System parameters of the playground model

\begin{tabular}{|c|c|c|c|}
\hline Parameter & Range & Default & Function \\
\hline Basic-R\&T-acceptance & $0-1$ & 0.25 & Mediate acceptance of $R \& T$ by receiver \\
\hline Beauty-stdev & $0-0.25$ & 0.25 & Random standard deviation initialisation of beauty \\
\hline Calling-distance & $1-6$ & 4 & Physical distance a-child can perceive other a-children to join \\
\hline Conferral-stdev & $0-0.2$ & 0.2 & Random component of conferrals \\
\hline FTol, fight-tolerance & $0-100$ & 0 & Cultural condemning / condoning of fighting, shared by all children \\
\hline Fight-penalty & $0-1$ & 0.1 & Status loss for picking a condemned fight \\
\hline Fight-threshold & $0-1$ & 0.2 & Status deficit above which a receiving a-child picks a fight \\
\hline GBR, girl-beauty ratio & $0-1$ & 0.5 & Beauty of girls compared to boys \\
\hline GKR, girl-kindness ratio & $0-1$ & 0.5 & Kindness of girls compared to boys \\
\hline GPR, girl-power ratio & $0-1$ & 0.5 & Power of girls compared to boys \\
\hline girl-R\&T ratio & $0-2$ & 0.1 & Multiplier for doing and liking R\&T of girls relative to boys \\
\hline IDV, individualism & $0-100$ & 50 & Modifies status-importance, segregation-tendency \\
\hline Interchild-gap & $1-4$ & 1.5 & Minimum distance between any a-children used during repositioning \\
\hline Intergroup-gap & $2-10$ & 3 & Minimum distance between a-children from different groups used during repositioning \\
\hline Kindness-stdev & $0-0.25$ & 0.25 & Random standard deviation initialisation of kindness \\
\hline Min-distance & $0-10$ & 2 & Spatial clustering within a group, looking for mate \\
\hline n-boys & $0-40$ & 20 & Number of a-boys in the classroom \\
\hline n-girls & $0-40$ & 20 & Number of a-girls in the classroom \\
\hline PDI, power-distance & $0-100$ & 50 & Modifies fighting-condemned?, status-importance \\
\hline Power-stdev & $0-0.25$ & 0.25 & Random standard deviation initialisation of power \\
\hline Rejection-penalty & $0-0.5$ & 0.2 & HBN loss to child that rejects attempt to join group, by rejected child \\
\hline R\&T-augmenter & $0-100$ & 0 & Extra status conferral percentage of $\mathrm{R} \& \mathrm{~T}$ \\
\hline R\&T-by-status? & $\mathrm{y} / \mathrm{n}$ & $\mathrm{y}$ & R\&T initiated by child with more status (or more power if R\&T-by-status? off) \\
\hline R\&T-offence? & $\mathrm{y} / \mathrm{n}$ & $\mathrm{n}$ & If yes, subtract / neglect unacceptable R\&T conferral to status \\
\hline R\&T-stdev & $0-0.2$ & 0.2 & \\
\hline R\&T-threshold & $0-1$ & 0.2 & Status surplus needed to consider doing R\&T \\
\hline sex-factor-on-conferral? & $\mathrm{y} / \mathrm{n}$ & $\mathrm{y}$ & Add GSG to conferral \\
\hline UAI, uncertainty-avoidance & $0-100$ & 50 & Modifies segregation-tendency \\
\hline Volatility & $0-0.2$ & 0.1 & Discount old values against latest one, for status and relationship \\
\hline$W_{\text {hbn R\&T }}$ & $0-1$ & 0.5 & Weight hbn during R\&T interpretation \\
\hline$W_{\mathrm{s}}$, status ratio & $0-1$ & 0.25 & Relative weight of the status of the other a-child's current status on the status conferral \\
\hline$W_{\mathrm{p}}$, personality ratio & $0-1$ & 0.25 & Relative weight of personality on the status conferral (i.e., my beauty and your kindness) \\
\hline$W_{\mathrm{r}}$ relationship ratio & $0-1$ & 0.25 & Relative weight of the relationship (hbn) on the status conferral \\
\hline
\end{tabular}

\subsection{Model analysis}

A one-at-a-time sensitivity analysis was conducted using the one-at-a time approach. Table 3, with the same parameters as in Table 3, presents the results. It is apparent from Table 3 that the highest effect of our dependent variable, GSG, is caused by parameters we explicitly designed to represent our interpretation of theory. The strongest effect is generated by R\&T-augmenter, a parameter we introduced to represent the status-boosting effect of being singled out for R\&T, that we deliberately gave a high value to highlight the effect of R\&T. This is followed by parameters we based on Kemper's theory: GBR, GKR, GPR, and sex-factor-on-conferral.

\subsection{Analysis of sources of status}

The fight-penalty and the three sources of status are selftheorised parameters. The sensitivity of the model to these parameters shows how the model works conceptually. It should be conceptually plausible. What follows is an anecdotal model analysis of these parameters, aiming to demonstrate this plausibility. Some of these could be made variable or context dependent in subsequent models, and varying them could be theoretically interesting; here we only want to convey a sense of their function. 
Fig. 4 Detailed process model of 'determine conferral' highlighting the role of R\&T. Legend: see Fig. 3

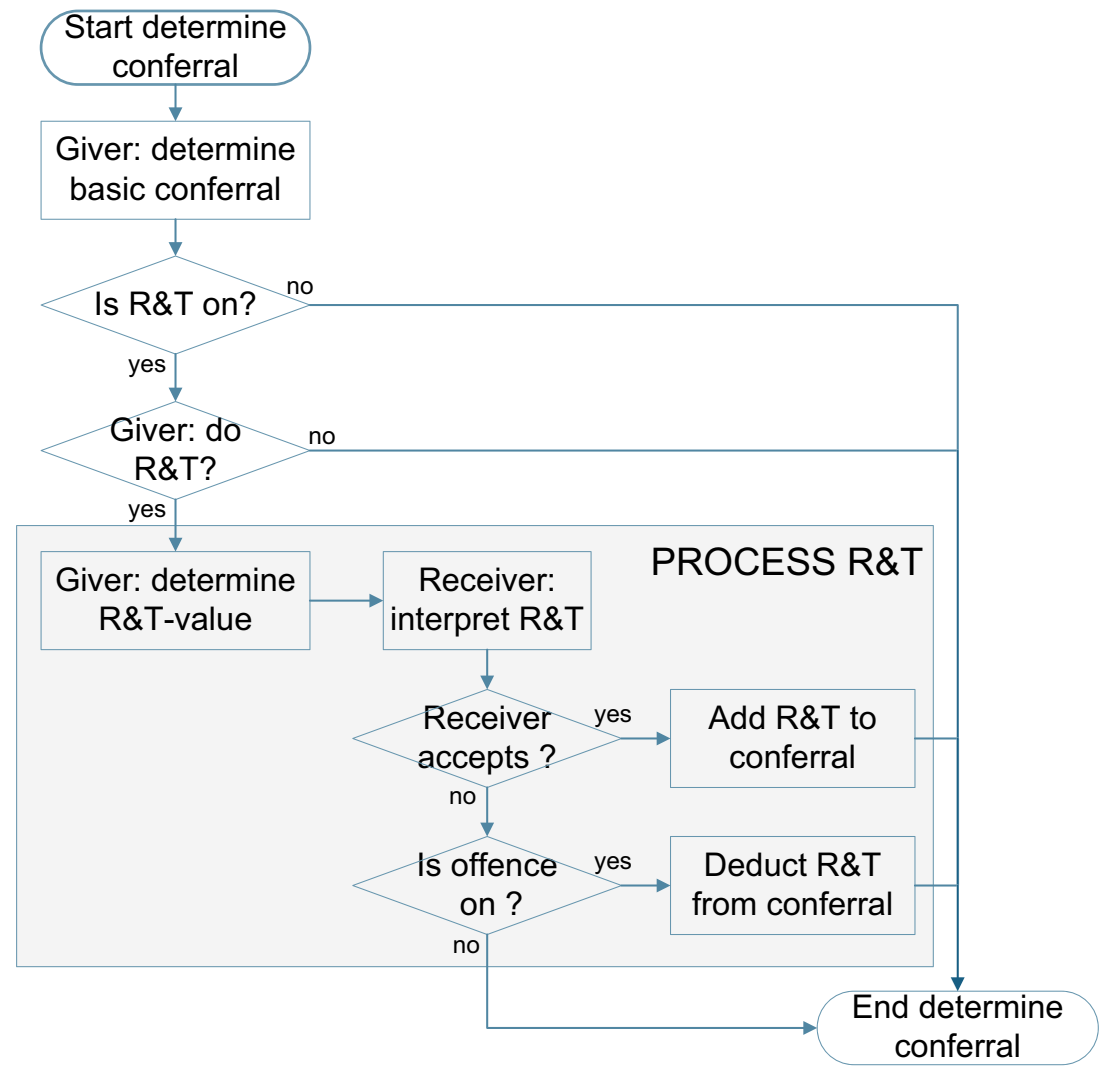

\subsubsection{Fight-penalty}

This is the status penalty incurred by the picker of a condemned fight. It is set at 0.1 . If zero, it can lead (after long runs) to a-children massively acquiring has-been-nice values of -1 with almost everyone else and stopping to find friends. If 0.2 , it tends to curb fighting.

\subsection{2 $W_{s}, W_{p}, W_{r}$}

These are the relative weights of the three sources of attraction (in Fig. 3: find-friend-or-group) and status conferral (Fig. 3: determine conferral): status, personality, relationship. They are normally set equal.

If $W_{\mathrm{s}}$ (status) is set to zero, many a-children lose their incentive to find friends and stay alone; apart from that, the model behaves normally. If only $W_{\mathrm{s}}$ counts, very steep status hierarchies can be generated by R\&T even in the absence of any difference in gender traits, and with fight-tolerance $=0$.

If $W_{\mathrm{p}}$ (personality) is set to zero, there is no fighting, because the variance generated by differences in beauty and kindness is removed from the model. If only $W_{\mathrm{p}}$ counts there is a lot of fighting even in fight-adverse cultures; children do not learn to find friends and avoid others, because there is no emerging landscape of relations and status.

If $W_{\mathrm{r}}$ (relationship) is set to zero, emergent status differences soar under the influence of R\&T, even in fight-adverse cultures. Relationships apparently mitigate the effects of status. If only $W_{\mathrm{r}}$ counts, a-children will not play at all, because they are not attracted; this is because the simulation starts without pre-existing relationships.

\section{Experiments}

We carried out the following experiments to test for our expected patterns. Each configuration of input parameters was run 50 times, which was sufficient to obtain small variances. All variables had their nominal values (see Table 3) except the one that was varied.

Pattern 1 (beauty comes to correlate with status for any set of parameter settings) we did not vary GBR. We carried out visual inspection of beauty distribution versus status distribution across all individual a-children at the end of each model run through a beauty versus status scatterplot. This is not shown; as an illustration, Fig. 5 shows a status-beauty correlation plot for one model run under FTol=0, Fig. 6 shows one under FTol $=100$. Pattern 1 was confirmed by both runs.

Pattern 2 (the status effect of kindness inversely correlates with fight-tolerance: being kind only gives status in a fight-averse culture) We fixed GPR $=.5$, no R\&T, varying 
Table 3 system parameters of the playground model with sensitivity analysis results of 50 runs each time

\begin{tabular}{|c|c|c|c|c|c|}
\hline Parameter & Nominal & Low value & High value & GSG effect & $\begin{array}{l}\text { GSG effect } \\
\text { normalised }\end{array}$ \\
\hline Basic-R\&T-acceptance & 0.25 & 0.2 & 0.3 & -0.0079 & -0.079 \\
\hline Beauty-stdev & 0.25 & 0.2 & 0.3 & 0.0072 & 0.072 \\
\hline Calling-distance & 4 & 3 & 5 & 0.0021 & 0.004 \\
\hline Conferral-stdev & 0.2 & 0.15 & 0.25 & -0.0030 & -0.030 \\
\hline FTol, fight-tolerance & 0 & 0 & 5 & 0.0057 & 0.115 \\
\hline Fight-penalty & 0.1 & 0.05 & 0.15 & -0.0040 & -0.040 \\
\hline Fight-threshold & 0.2 & 0.15 & 0.25 & 0.0011 & 0.011 \\
\hline GBR, girl-beauty ratio & 0.5 & 0.45 & 0.55 & -0.0445 & -0.445 \\
\hline GKR, girl-kindness ratio & 0.5 & 0.45 & 0.55 & -0.0239 & -0.239 \\
\hline GPR, girl-power ratio & 0.5 & 0.45 & 0.55 & -0.0193 & -0.193 \\
\hline Girl-R\&T ratio & 0.1 & 0.05 & 0.15 & -0.0039 & -0.039 \\
\hline IDV, individualism & 50 & 45 & 55 & 0.0125 & 0.125 \\
\hline Interchild-gap & 1.5 & 1.4 & 1.6 & -0.0022 & -0.054 \\
\hline Intergroup-gap & 3 & 2.9 & 3.1 & 0.0056 & 0.140 \\
\hline Kindness-stdev & 0.25 & 0.2 & 0.3 & 0.0039 & 0.039 \\
\hline Min-distance & 2 & 1 & 3 & -0.0120 & -0.030 \\
\hline n-boys & 20 & 19 & 21 & 0.0000 & 0.000 \\
\hline n-girls & 20 & 19 & 21 & -0.0019 & -0.019 \\
\hline PDI, power-distance & 50 & 45 & 55 & -0.0051 & -0.051 \\
\hline Power-stdev & 0.25 & 0.2 & 0.3 & 0.0003 & 0.003 \\
\hline Rejection-penalty & 0.2 & 0.15 & 0.25 & 0.0135 & 0.135 \\
\hline R\&T-augmenter & 0 & 0 & 5 & 0.0842 & 1.684 \\
\hline R\&T-by-status? & $\mathrm{y}$ & $\mathrm{n}$ & $\mathrm{y}$ & -0.0081 & -0.008 \\
\hline R\&T-offence? & $\mathrm{n}$ & $\mathrm{n}$ & $\mathrm{y}$ & 0.0027 & 0.003 \\
\hline R\&T-stdev & 0.2 & 0.15 & 0.25 & 0.0030 & 0.030 \\
\hline R\&T-threshold & 0.2 & 0.15 & 0.25 & 0.0068 & 0.068 \\
\hline Sex-factor-on-conferral? & $\mathrm{y}$ & $\mathrm{n}$ & $\mathrm{y}$ & 0.0289 & 0.029 \\
\hline UAI, uncertainty-avoidance & 50 & 45 & 55 & 0.0022 & 0.022 \\
\hline Volatility & 0.1 & 0.05 & 0.15 & 0.0052 & 0.052 \\
\hline $\begin{array}{l}W_{\text {hbn R\&T }}, \text { hbn-weight-in-R\&T- } \\
\text { acceptance }\end{array}$ & 0.5 & 0.45 & 0.55 & -0.0095 & -0.095 \\
\hline$W_{\mathrm{s}}$, status ratio & 0.25 & 0.2 & 0.3 & -0.0114 & -0.114 \\
\hline$W_{\mathrm{p}}$, personality-ratio & 0.25 & 0.2 & 0.3 & -0.0076 & -0.076 \\
\hline$W_{\mathrm{r}}$, relationship-ratio & 0.25 & 0.2 & 0.3 & -0.0022 & -0.022 \\
\hline
\end{tabular}

GKR and FTol. Figure 7 shows the results: pattern 2 was confirmed.

Pattern 3 (as an exception to pattern 2, in fight-tolerant cultures, weak children can avoid status loss if they are kinder) As pattern 2 but at GPR $=.25$ (weaker girls). Figure 8 shows the results: pattern 3 was confirmed, but only for extreme FTol / GKR combinations.

Pattern 4 (the status effect of power is mediated by fighttolerance; in a fight-averse group, power is irrelevant while in a fight-tolerant group it is the main source of status) Comparison of the line FTol $=0$ across Figs. 7 and 8 shows hardly any difference. At FTol $=100$, however, the weaker girls of Fig. 8 incur a status loss of 0.1 to 0.3 status point, more so if they are less kind. Also Figs. 5 and 6 give a visual impression at individual level in the power-status plots. Pattern 4 was confirmed.

Pattern 5 (in groups where boys do more R\&T than girls, they will gain status in terms of gender status gap (GSG)) We fixed GKR $=.5$ and FTol $=50$, and varied GPR and R\&T. Figure 9 shows the results. They confirm pattern 5 .

Pattern 6 (if children (mostly girls) place greater weight on relationship relative to status and personality, they can offset status loss through $R \& T$ ) We fixed GKR $=.5$ and $\mathrm{FTol}=50$, varying GPR and $\mathrm{W}_{\mathrm{r}}$. Figure 10 shows the results, which confirm pattern 6 .

Pattern 7 [In a fight-tolerant culture, $R \& T$ penalises its users (mostly a-boys) if many receivers (of both sexes) take offence to $R \& T]$ We used the runs mentioned under 
Fig. 5 One model run after 300 ticks. Graphs show status distribution, GSG, and relation of status with personal traits (beauty, power, and kindness) of 20 a-boys and 20 a-girls. $\mathrm{GKR}=0.5$ and $\mathrm{GPR}=0.5 . \mathrm{R} \& \mathrm{~T}$ was off, $\mathrm{FTol}=0$. Each dot on the right-hand side represents one a-child
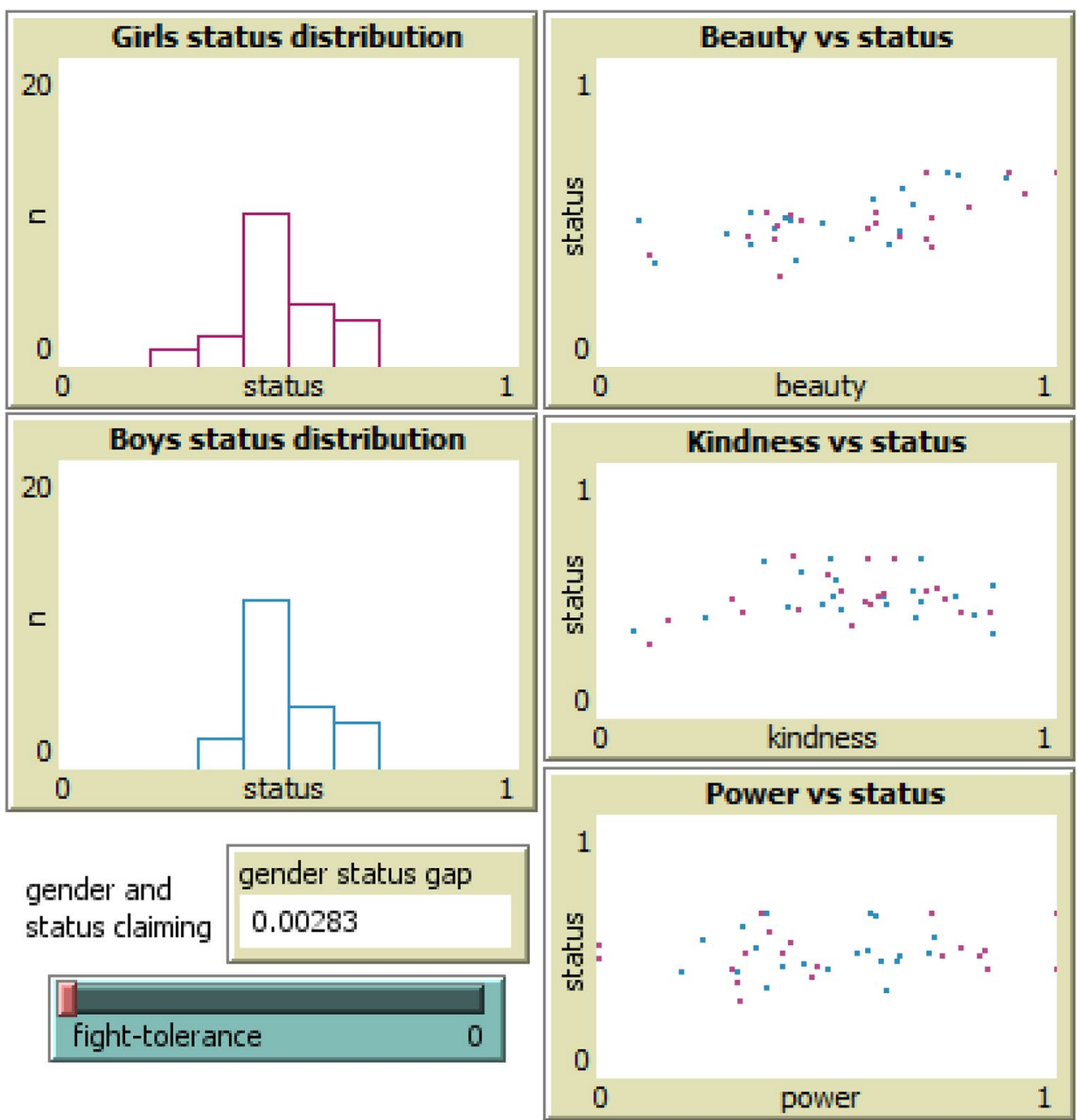

pattern 5. The rightmost six bar charts in Fig. 9 show the results. We did a further test at GPR $=.75$ (stronger girls) and R\&T-offence on, varying GKR and FTol, shown in Fig. 11. Pattern 7 was falsified.

\section{Results}

Every parameter setting leads to stable patterns with some variation between runs depending on the random seed and numbers of a-children, i.e., the particular classroom being modelled. During the first 100-150 ticks of a simulation run, the frequency of unhappy conferrals changes most; apparently a-children learn to pick their friends through emerging friendships (the has-been-nice dyadic memory mechanism) and emerging status landscapes. Thereafter, a pattern of fluctuation persists. With different initialisations as to status distribution of the a-children, the simulation converges to the same pattern.

\subsection{Pattern 1: Beauty gives status}

Pattern 1 occurred in any run, whatever the other variables; we did not conduct separate runs to test it. To provide an impression, Figs. 5 and 6 show the results of two sample runs of the same 40 a-children, under extreme FTol values. Visual inspection shows a positive correlation of status with beauty in both cases.

In the remainder of this article, all model runs consist of 300 ticks with 20 a-girls and 20 a-boys that were heterogeneous in kindness, beauty, and power but had equal initial status. Fifty runs with different a-children were repeated per condition; the effects of all variables on GSG, except FTol, are significant at $p<0.0001$. 
Fig. 6 Same classroom and parameters as in Fig. 5, except FTol $=100$
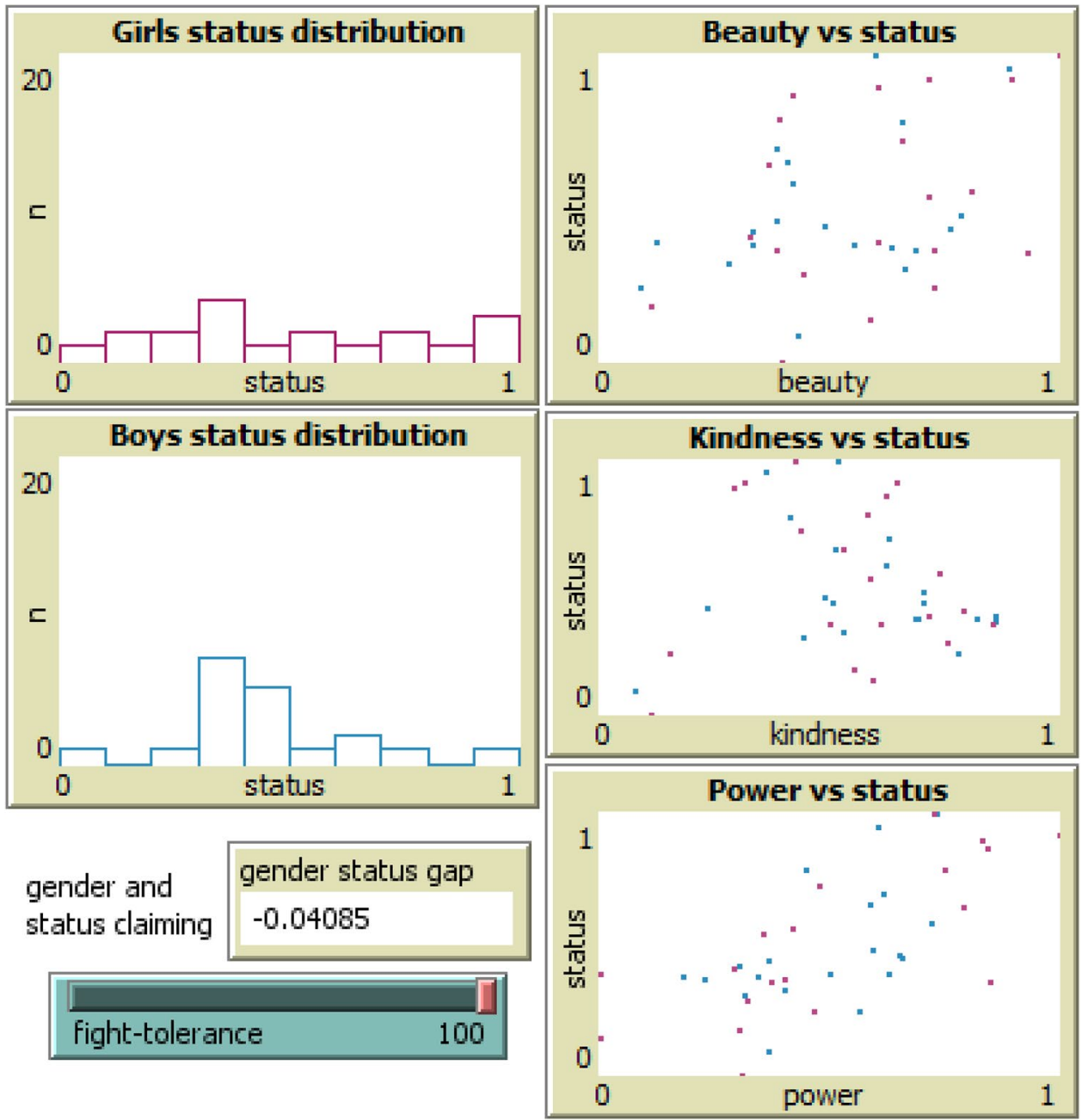

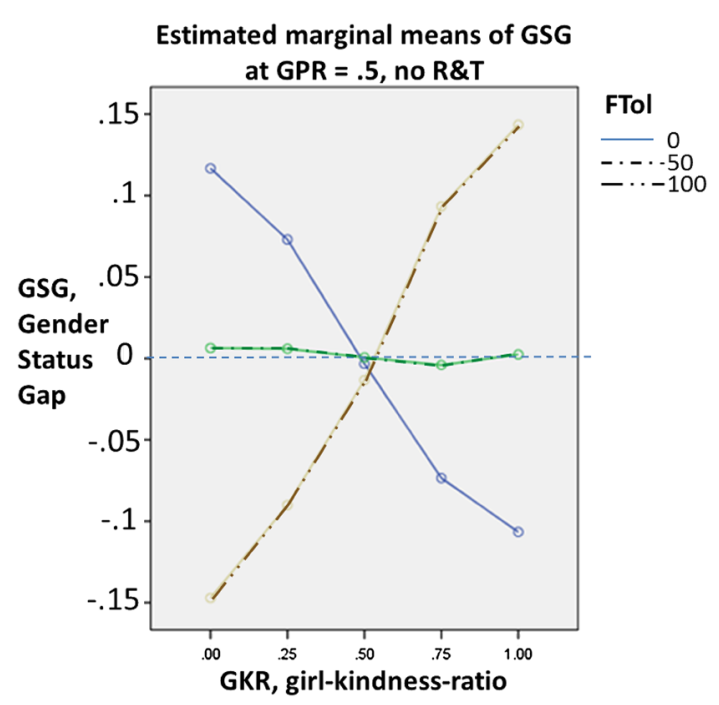

Fig. 7 Averages of 50 runs. GSG plotted vertically, GKR horizontally. GPR $=0.5$, no R\&T, three FTol levels

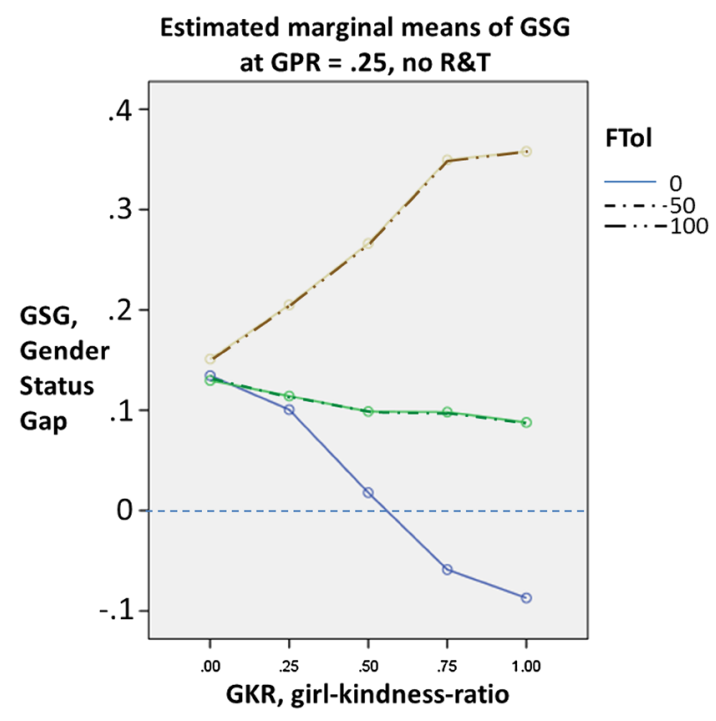

Fig. 8 Averages of 50 runs. GSG by GKR at GPR $=0.25$, without R\&T, for three FTol levels 
Fig. 9 Averages of 50 runs. GSG by GPR at GKR $=0.5$ and FTol $=50$ under three behavioural settings. Left: no R\&T, middle: R\&T with R\&T-offence off, right: R\&T with R\&Toffence on. Stdevs are 0.04-0.06 status points
Fig. 10 Average of 50 runs. GSG by GPR at increased weight of has-been-nice $\left(W_{\mathrm{r}=}\right.$ 0.25 is the baseline condition for all other model runs). $\mathrm{GKR}=.5, \mathrm{FTol}=50$. Stdevs are $0.02-0.04$ status points
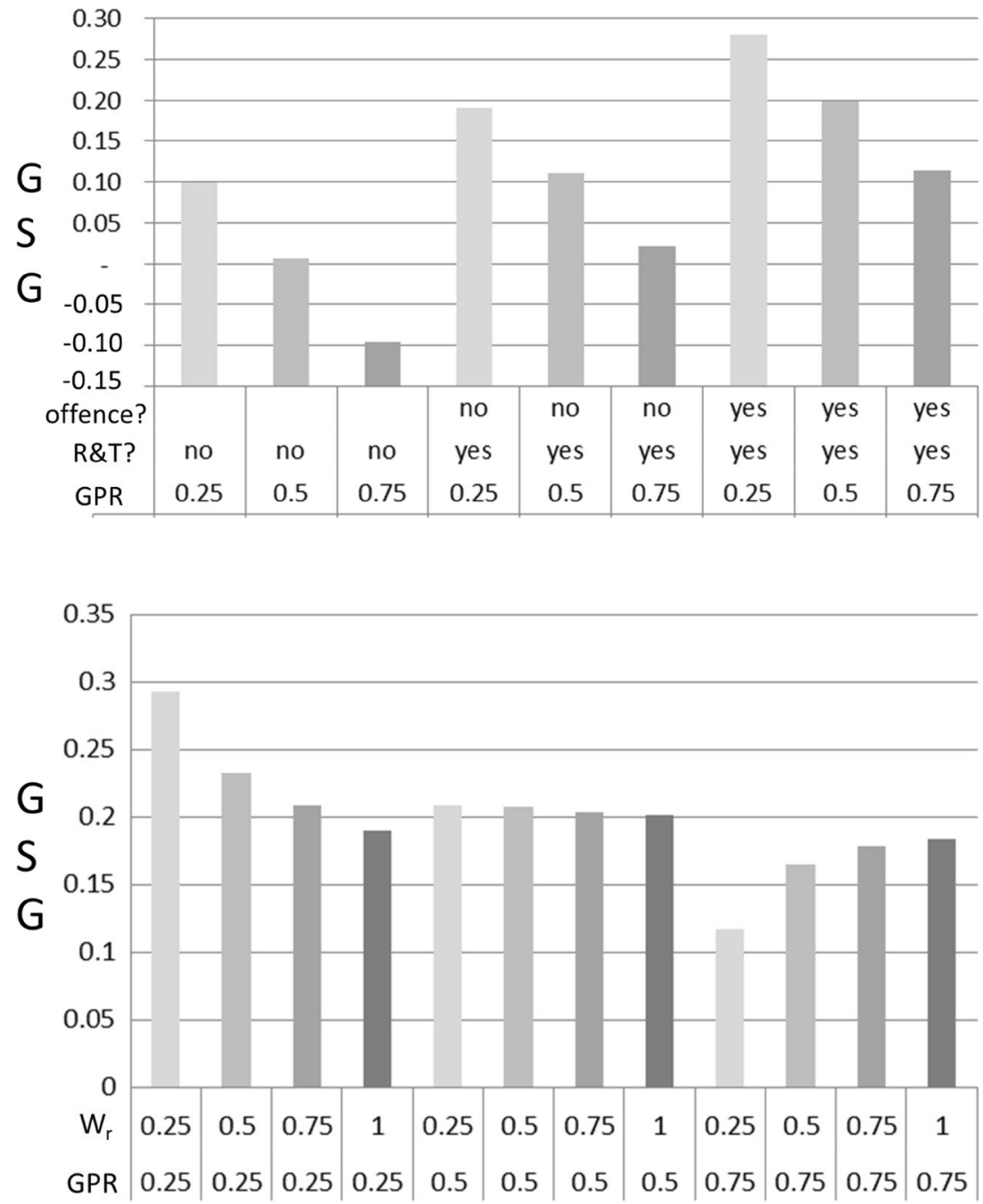

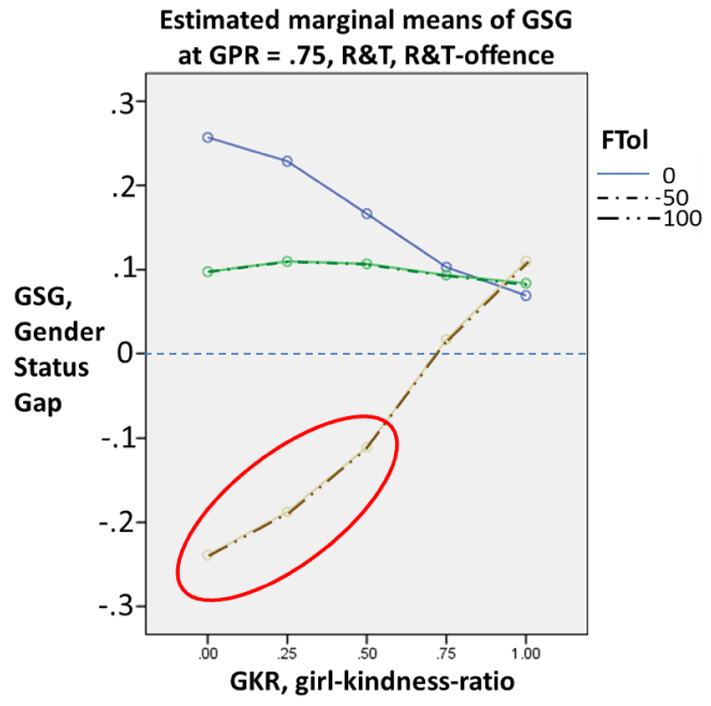

Fig. 11 Averages of 20 runs. GSG by GKR at GPR $=0.75$, with $R \& T$, girl-R\&T=0.1, R\&T-offence on. Top line: FTol=0, middle line FTol $=50$; bottom line: $F T o l=100$. The oval shows conditions where the a-girls draw status advantage from their superior power

\subsection{Pattern 2: be kind unless fighting is rampant}

Figure 7 shows results without R\&T, and with girl-power equal to boy-power on average. As expected, the outcomes are symmetrical around $\mathrm{GSG}=0$. At FTol $=0$, the model reproduces the proverbial "do good and good will come to you". At FTol =100, kind a-children who accept lower status conferrals rather than picking fights, retain a low status. This leads to a classroom in which strong unkind a-children acquire high status through force.

At extreme values of GKR, we see larger GSG at $\mathrm{FTol}=100$ than at $\mathrm{FTol}=0$. This is because at $\mathrm{FTol}=100$, more fighting happens than at $\mathrm{FTol}=0$, allowing strong a-children of the unkind sex to compensate for status losses by winning fights against high-status a-children. At FTol $=0$, strong, unkind a-children who try fighting only suffer blame and status loss.

We conclude that pattern 2 receives strong support. The status value of kindness depends strongly on culture. 


\subsection{Pattern 3 and 4: modest effect of being strong or weak}

We established the effect of varying a-boys' power relative to a-girls' in the absence of R\&T (see Fig. 7 (GPR 0.5) and 8 (GPR 0.25)).

Figure 8 shows that even if a-girls are markedly less powerful than a-boys, they can gain more status on average than a-boys, as long as the culture is fight-averse $(\mathrm{FTol}=0)$ and they are kinder than a-boys. Kinder a-girls confer more status, thereby making friends through has-been-nice. Additionally, at FTol =0, a-boys will lose status if they pick fights. A-girls learn to avoid unfriendly a-boys through hasbeen-nice. So, the effect of even a huge power difference is modest. At FTol = 50, almost regardless of their kindness, girls at GPR 0.25 will have about a 0.1 gender status deficit on average.

At FTol $=100$ girls can limit status loss by being radically unkind $(\mathrm{GKR}=0)$. When girls are kinder than boys they do not incur much status loss beyond GKR $=0.75$. This is because they already lose to a-boys anyway, and so excessive kindness $(\mathrm{GKR}=1)$ can hardly result in more lost fights, while it can improve friendships among the a-girls.

All in all, we only find weak evidence for pattern 3 for $\mathrm{FTol}=100$ and $\mathrm{GKR}=100$, that is, at extremes of the distribution.

Pattern 4, on the contrary, is strongly supported at group level. Figures 7 and 8 show near-identical lines at FTol $=0$, a similar line but at around 0.1 higher GSG for FTol $=50$, and a flatter line with a GSG depression at high GKR for FTol $=100$. At Ftol $=0$, power in terms of GPR is indeed irrelevant. The effect at individual level is similar. This can be gleaned by comparing the power versus status scatterplots in Figs. 5 and 6.

\subsection{Patterns 5, 6, and 7: rough-and-tumble boosts status}

We fixed GKR and FTol at average values and investigated the effect of R\&T with and without R\&T-offence (Fig. 9).

Pattern 5 was confirmed. Figure 9 shows how R\&T boosts GSG by about 0.1 , more so under low GPR. This also holds for many other settings of GKR and FTol not shown in the figure. In conclusion, in this model, it pays to do R\&T. Contrary to expectations for pattern 7 , turning on R\&T-offence increases the group-level status-boosting effect of R\&T. This even happens when girls are stronger, at GPR $=0.75$. We carried out another test for pattern 7 , see below.

Pattern 6: We investigated whether a stronger role for hasbeen-nice could moderate the effect of GPR on GSG with R\&T and R\&T-offence on (Fig. 10). We increased has-beennice importance relative to beauty, kindness, power, and status in the attraction and conferrals logic for both sexes. It turns out that a-girls, when they are weaker than boys, can protect their status by enhancing their attention for dyadic relationships compared to personality and status. This no longer works when a-girls are stronger.

Finally, we investigated what would happen if boys did more R\&T while girls were stronger and R\&T-offence? was on (Fig. 11).

The results are striking. While without $R \& T$, the a-girls would have had a favourable GSG of -0.1 on average at GPR $=0.75$, with R\&T and R\&T-offence on, a-girls' status is actually lower than a-boys' status by more than 0.1 . Inspecting individuals shows that a few powerful a-girls achieved alpha status. The only group condition under which a-girls can collectively draw status from their power is at low GKR and high FTol.

Pattern 7 is falsified by Fig. 9: R\&T-offence does not diminish but boosts the GSG at FTol $=50$. Figure 11 shows that, given that in terms of status R\&T is always bad for the sex that does it less, unkindness is what can help strong girls resist the collective status loss R\&T engenders, but only at extremely high values of FTol $(=100)$. Inspection of many runs shows that this effect also occurs at individual level: strong, unkind girls can achieve high status.

\section{Discussion}

In the theory section, seven patterns were mentioned that we expected to emerge during simulation runs. We found six and falsified one. We expected R\&T to penalise its users if the receivers took offence at the $\mathrm{R} \& \mathrm{~T}$, but found the opposite. The interesting point is the mechanism by which a pattern unfolded. For the patterns that were not obvious, we shall discuss mechanisms in what follows, ordered roughly by traits (kindness and power), behavioural strategy (R\&T), and culture. Then, we switch to some general points: validation, methodology, policy implications, and extensions. Among the latter, the possible use of the model for adult behaviour is given special attention.

\subsection{Kindness}

The status effects of kindness depend on culture (pattern 2). When a-girls are kinder this is good for their status in fightintolerant cultures, but bad in fight-tolerant ones. There is one exception: at GPR $=0.25$, being kinder than $\mathrm{GKR}=0.5$ does not cost girls any more status, whatever the culture (pattern 3 then holds for all values of FTol). In effect, when boys are markedly stronger, both boys and girls get more status as a sex by developing complementary strategies. Boys win status by focusing on R\&T (pattern 5) while girls win status by focus on kindness and relationships (pattern 6). Interestingly, this kind of dichotomy is precisely the pattern 
that has been found empirically as occurring in diverse professions, societies, and experiments when one of two groups is perceived as stronger (Ridgeway 2011, chapter three). It could be that this pattern automatically emerges in any social group with status-power dynamics that has a binary split along power lines. A 'frailty myth' for one sex can thus create a lock-in.

\subsection{Power}

Folk psychology may hold that boys have more status in society because they are physically stronger. The ABM shows a limited effect of physical power by itself on GSG. At GPR $=0.25$, a-boys have a power surplus of on average 0.29 which gives them only about a 0.06 status surplus at $\mathrm{FTol}=50$ without R\&T.

\subsection{Rough-and-tumble}

In model runs with R\&T, a-boys were ten times more likely to use it than a-girls. Our modelled R\&T has no direct status benefits for the giver, only for the receiver. Yet R\&T produced the group-level effect of increasing the gender status gap favouring a-boys. This effect occurred across a wide range of settings for relative kindness and power of a-girls and a-boys, as well as a wide range of cultures in terms of fight-tolerance. It was not found in the literature, so it can be considered a contribution by the ABM. Naturally, empirical studies need to corroborate this finding. We can note that our model worked with a big status bonus for conferrals with R\&T (through R\&T-augmenter), to which the model was highly sensitive (Table 3 ). In reality, more subtle forms of $R \& T$ could occur next to these obvious ones.

R\&T boosts the status of those who do it (pattern 5) even more if R\&T-offence is on (pattern 7). Apparently, at classroom level, a-boys learn to avoid the angry a-girls and search one another out so that extra status conferrals that a-boys mutually confer upon one another through R\&T outweigh the penalty inflicted upon them by a-girls.

The literature says more popular children initiate R\&T, and this is the normal setting in the model. We experimented with R\&T initiation by a-children with more power instead of more status, through the switch R\&T-by-status?. This led to slightly less status gain for those that did R\&T, except at low GKR and Ftol $=100$. We did not pursue this alley.

Figure 11 shows that differences in R\&T have more influence on GSG than power differences. This is a clear case of 'nurture above nature' in social dynamics. If the model effect holds for real societies, then R\&T, with its peak in early adolescence, acts as a status changer between the sexes favouring boys. Learning to deal with both R\&T use and reception during childhood could be an important element of gender-balanced education.
Pattern 6 is the only one that we investigated by modifying the relative weight of relationships as sources of attraction and status conferral, by making $\mathrm{W}_{\mathrm{r}}$ relatively more important compared to $W_{\mathrm{p}}$ and $W_{\mathrm{s}}$. Its effects were clear, especially for the weaker sex (Fig. 9).

\subsection{Culture}

Under all settings, a fight-tolerant culture benefitted the more powerful and/or less-kind sex. For example, strong a-girls could gain the upper hand in the status balance as a group if they were unkind (Fig. 11), and individually, strong a-girls could fight their way up (see the 'Girls status distribution' window in Fig. 6).

Another effect considered cultural is the relative importance of dyadic relationships versus public individual attributes. We found that a-girls who were weaker than a-boys, in settings with R\&T and R\&T-offence on, would benefit in status if they attached relatively more importance to dyadic relationships. Interestingly, personal relationships are found to be more important to girls than to boys among schoolchildren. These close relationships could have the rewarding effect of providing mutual status conferrals if others are not willing to provide them.

\subsection{Validation}

These results from a simple ABM provide encouragement that this model based on Kemper's theory is worth developing further. Empirical studies across schools with different social acceptability of fighting, mapped to the model's fighttolerance, could be used for validating the model. In the model classroom effects are strong, particularly in smaller classes than used in this article, depending on the random assignment of traits to a-children. It would be interesting to follow path dependent microdynamics of a-children and friendships. Attribute combinations can make certain behaviours likely; for instance, a popular, unkind a-child could behave as a bully to achieve a higher status.

\subsection{Methodological remarks}

This study confirms that using ABMs in social science can be valuable for theory development and testing for social concepts that are difficult to experiment with. As such, it takes a step further in a direction that has already been advocated. In a visionary paper, Sandra Scarr argued that diverse theoretical resources were called upon to "explain becoming human and becoming a member of society" (Scarr 1993, p. 1333). She explicitly included the aggregation levels of the individual and society. She also stated that both biological and social sciences are needed. 
On the nature-nurture theme, the pendulum has swung from one side to the other through the decades (Sameroff 2010). Sameroff emphasises the interconnectedness between the individual and its context. Several child development researchers have argued that complex dynamic systems methods can uncover emergent phenomena in ways that are hard to discover otherwise (Lewis 2000; van Geert 2011), and that computational models allow investigating possible self-organisation of development outcomes.

Scarr's point about aggregation levels has been reiterated by sociologists (Jepperson and Meyer 2011). They argue that multiple levels of analysis, the individual and the social system, are needed to explain social dynamics.

$\mathrm{ABMs}$ that focus purely on the social side of interaction are rare in the literature. One work on reputation is reminiscent of Kemper's status (Sabater-Mir et al. 2006). Another publication on social importance theory has a strong status exchange component, but its aim is human-agent interaction in a virtual world, as opposed to simulating the dynamics among the agents (Mascarenhas et al. 2013).

ABM applications usually integrate the instrumental side ('getting something done') and the purely social side ('relating to others') of interaction (Grow et al. 2015; Wilson 2007). This tends to lead to ad-hoc, situational implementations of the social side. In contrast, researchers advocate using generic building blocks in ABM (e.g., Goldspink 2000; Hamill 2010). Our approach aims to do this by first creating a stand-alone investigation of the social side. If validated, it could be used as a generic social building block in an agent architecture that can also model instrumental actions.

\subsection{Policy implications}

We set out to investigate the question: "How important are sex traits, behaviours, and gendered beliefs, in causing a status gap between the sexes?" On the hypothesis that such a status gap is undesirable, that question translates as "how could we reduce such a status gap?" Our model shows that the most effective way would be to reduce fight-tolerance. Many educators would favour changing the classroom culture into one that is less fight-tolerant; however classrooms are embedded into schools and societies. One does not simply change a culture (Lansu et al. 2013). Possible measures could be related to play and conflict. To teach the children constructive use of R\&T, one could engage the classroom in forms of play that are gradually less supervised. For the staff to give the example in resolving conflict-prone situations without resorting to force is another possible measure.

If these measures are impossible or ineffective, the second option apparent from our model would be to make girls less meek (as per Fig. 11). The model shows that it is not so much their actual physical power as their tendency to put up with low conferrals that damages their status. This could help individual girls, but it would not reduce antagonistic interactions.

Another point concerns the distinction between friendly R\&T and nasty bullying. In real life, the distinction between bullying and R\&T can be ambiguous. Let us suppose that R\&T can lead to bullying when rejected by those on whom it is done. If bullying is rife at a certain school, should bullies be punished? This will make them fear punishment, but it will not change the children's incentives. Punished bullies may even be motivated to seek revenge. Worse, it reinforces fight-tolerance as a cultural trait, since the teachers endorse using force via punishment. Instead, it could be more fruitful to teach all children to deal with R\&T in a constructive way before bullying has had time to establish itself, so that they learn to accept and reciprocate playful fighting. This capacity to reciprocate actually distinguishes popular from rejected children (Pellegrini and Smith 1998), and developing it may be the most effective anti-bullying strategy.

\subsection{Conceptual extensions}

The playground simulation model is also a playground for testable hypotheses. Scholars who want to scrutinise our interpretation of R\&T or fight-tolerance, for instance, could adapt the model to their theories and frameworks. Personality psychologists might want to include more complex personality elements such as the big five personality traits.

The model's architecture offers lots of opportunities. For instance, R\&T as a preponderantly male strategy of combining a power move and a status conferral could be supplemented with a mostly female equivalent such as using the historical relationship to further the individual's status. A taste of this is given in Fig. 10 where we increased the relative weight of has-been-nice.

The current ABM has some obvious limitations. First, status claims are important in Kemper's model, but not modelled explicitly here. Current scalar status, used by the agent as a lower limit of acceptance of conferrals, is an implicit status claim. Doing R\&T could be construed as a disguised status claim. In our model it is a conferral, yet interestingly it leads to the group-level outcome of higher status on average for those doing it, at least partly through improved dyadic relationships. Explicit claims could also be modelled to be accepted, neglected, or actively fought.

Second, group-level agency is missing from the model. Experiments with model versions that had more group agency showed that group longevity and size can be much affected, and in plausible ways, by letting entries, fights, and exits be moderated by who is in the group. These aspects merit further study.

A third aspect not operational in the playground model, while obviously relevant to social life, is social identity. 
Young children frequently make gender attributions, as was evident from the ethnographies studied (Thorne 1993; Woods 2013). A proper treatment of social identity would require binding the status concept to different groups or categories. An a-child could then have different status in the various groups to which it belonged, in accordance with Kemper's theory (ibid., p. 16). In the classroom context, these could be cliques based on personal relationships, or gender categories. We experimented with a simple conceptualisation; a 'prejudice factor' could be turned on that discounted every status conferral based on the existing GSG. This preserved all the trends shown in the article, while more or less doubling their effects.

Fourth, the model would allow investigating distributional differences between boys and girls. If variances in traits are larger for boys than for girls, as Eliot finds in many areas, then boys might be overrepresented both among dropouts and among top dogs. We did not investigate this gender difference in variability for the present article.

Finally, the playground model also lends itself to investigating cross-cultural differences. A precursor has been used for that purpose (G. J. Hofstede 2013). A limitation of such a broad behaviour model is that it can hardly be validated through empirical research. The present model has some plausibility in explaining the gender status pattern found (Evaldsson 2003; Thorne 1993) if we assume that the US and the Swedish schools have inherited the cultural masculinity levels of their respective societies. In the future, it would be worthwhile to try a more systematic cross-cultural investigation of the playground model.

\subsection{Can this model be used for modelling adults?}

We believe that the validity of the status-power theory driving the agents in this simulation is not limited to children. This model lends itself to being adapted to multiple social situations, such as organisational behaviour, policy making, and politics. Let us argue the validity of this claim.

Firstly, Kemper explicitly claims that his theory is comprehensive and applies to everyone, everywhere. Our model is generic across Kemper's theory and could therefore be extended to other situations. A cocktail party, for instance, would be similar to our playground. If we were to extrapolate to more realistic situations we might have to include other measures of status worthiness. A fuller model would include multiple group memberships for an agent with potentially different status, and ensuing movements of agents to groups that confer more status on them.

Secondly, what does the insight that rough-and-tumble play affects status attainment in school classes tell us about status attainment in society at large, given that pushing and shoving is usually not an accepted behaviour in most adult contexts? Are there adult forms of R\&T? We believe that
$\mathrm{R} \& \mathrm{~T}$ is a special case of affiliative dominance interactions that can be extrapolated to adults, where it tends to take on less physically visible forms. Use of personal proximity, assertive tweets, speech or actions, or asymmetry of touching based on position and gender, are examples of behaviours that can be ambiguous. They may mix friendly intentions and dominance messages (Major 1981). 'Let's twist his arm a bit', in a business context, connotes similar action. In conclusion, an abstract model such as ours could be adapted to 'adult R\&T'.

Thirdly, what about culture? We are convinced that this model could be complemented with other aspects of culture. Dimensional models lend themselves very well for this. For instance, some of the literature findings we discussed in the 'culture' section could be addressed by including Hofstede's power distance, i.e., the tendency to defer to someone with more status, as a model parameter.

We conclude that this kind of broad-purpose model of social life can be used more widely, when adaptations are made to intended contexts of use. If models of socio-technical or socio-ecological systems require social agents, then the social arena model can be a good starting point.

\section{Conclusion}

This article presents a comprehensive agent-based model of social behaviour, by means of the example of middle youth children playing on a school playground in mixed-sex groups. The individual level and its interactions are interpreted using Kemper's status-power theory of social relations, as well as empirical work on R\&T among children, and cross-cultural theory. By repeated runs of the model, one can study the same virtual classroom with different assumptions of cultural fight-tolerance, or different randomly created classrooms with the same parameters.

Under our assumptions, the simulation reproduces phenomena found in research on children and social status. In this model, nurture beats nature: differences in dispositional factors (kindness and power) play out very differently in terms of social status effects depending on the social acceptance of fighting, or on gender-based 'prejudice'. At classroom level, the strategic use of R\&T with children of slightly lower status than one's own boosts status for those who do it, even when the receivers take offence at the R\&T. All in all, both R\&T and culture mediate the contribution of physical power to social status. The results are relevant for research on bullying and on school climate.

In terms of emerging classroom-level gender status gap this means that if boys do more R\&T than girls, regardless of how fight-tolerant the classroom culture is, this boosts their collective status. If there also is a fight-tolerant culture, this effect of R\&T is amplified. Even if girls are physically more 
powerful this does not undo the joint effect of R\&T and fight-tolerance, except if girls are extremely unkind compared to boys, and likely to pick fight at every R\&T action by boys. In our model, placing more weight on dyadic relationship compared to public status could alleviate status loss; this seems indeed to be a strategy used by girls. The current model is a first step in what could become a promising line of research for issues that are hard to study empirically, but show robust patterns recognised by educators.

In conclusion, theory-driven agent-based modelling has merit for studying causation of pattern in child development. The theory driving these artificial children is so generic that model extensions for other social situations involving adults are equally possible. Hence the title 'status arena'; our social lives, also as adults, abound with status arenas. The status-power dynamics of these could be studied with models like the one introduced here.

Acknowledgements The authors thank NIAS, Netherlands Institute for Advanced Studies in the Social Sciences and humanities, for enabling the work leading to this study. Comments by Josephie Brefeld, Katy Hofstede, Theodore Kemper and anonymous reviewers have greatly improved the article.

Open Access This article is distributed under the terms of the Creative Commons Attribution 4.0 International License (http://creativecommons.org/licenses/by/4.0/), which permits unrestricted use, distribution, and reproduction in any medium, provided you give appropriate credit to the original author(s) and the source, provide a link to the Creative Commons license, and indicate if changes were made.

\section{References}

Bai F (2016) Beyond dominance and competence a moral virtue theory of status attainment. Personal Soc Psychol Rev 1088868316649297

Baillargeon RH, Zoccolillo M, Keenan K, Côté S, Pérusse D, Wu H-X, Tremblay RE (2007) Gender differences in physical aggression: a prospective population-based survey of children before and after 2 years of age. Dev Psychol 43(1):13. https://doi. org/10.1037/0012-1649.43.1.13

Baron AS (2015) Constraints on the development of implicit intergroup attitudes. Child Dev Perspect 9(1):50-54. https://doi.org/10.1111/ cdep. 12105

Campbell DW, Eaton WO (1999) Sex differences in the activity level of infants. Infant Child Development 8(1):1-17

Cillessen AHN, Mayeux L (2004) From censure to reinforcement: developmental changes in the association between aggression and social status. Child Dev 75(1):147-163. 0009-3920/2004/7501-0010

Cole PM, Bruschi CJ, Tamang BL (2002) Cultural differences in children's emotional reactions to difficult situations. Child Dev 73(3):983-996. https://doi.org/10.1111/1467-8624.00451

Crick NR (1996) The role of overt aggression, relational aggression, and prosocial behavior in the prediction of children's future social adjustment. Child Dev 67(5):2317-2327. https://doi. org/10.1111/j.1467-8624.1996.tb01859.x
DiPietro JA (1981) Rough and tumble play: a function of gender. Dev Psychol 17(1):50. https://doi.org/10.1037/0012-1649.17.1.50

Dowling C (2000). The frailty myth. Women approaching physical equality: Random House

Eliot L (2009) brain, blue brain: how small differences grow into troublesome gaps-and what we can do about it. Mariner Books, Boston

Ellis WE, Zarbatany L (2007) Peer group status as a moderator of group influence on children's deviant, aggressive, and prosocial behavior. Child Dev 78(4):1240-1254. https://doi. org/10.1111/j.1467-8624.2007.01063.x

Evaldsson A-C (2003) Throwing like a girl?: Situating gender differences in physicality across game contexts. Childhood 10(4):475497. https://doi.org/10.1177/0907568203104006

Farver JAM, Shin YL (1997) Social Pretend Play in Korean- and Anglo-American Preschoolers. Child Dev 68(3):544-556. https:// doi.org/10.1111/j.1467-8624.1997.tb01957.x

French DC, Jansen EA, Pidada S (2002) United States and Indonesian Children's and adolescents' reports of relational aggression by disliked peers. Child Dev 73(4):1143-1150. https://doi. org/10.1111/1467-8624.00463

French DC, Chen X, Chung J, Li M, Chen H, Li D (2011) Four children and one toy: Chinese and Canadian children faced with potential conflict over a limited resource. Child Dev 82(3):830-841. https:// doi.org/10.1111/j.1467-8624.2011.01581.x

Gifford-Smith ME, Brownell CA (2003) Childhood peer relationships: social acceptance, friendships, and peer networks. J Sch Psychol 41:235-284. https://doi.org/10.1016/S0022-4405(03)00048-7

Goldspink C (2000). Modelling social systems as complex: Towards a social simulation meta-model. J Artif Soc Soc Simul, 3(2). http:// jasss.soc.surrey.ac.uk/3/2/1.html

Grimm V, Polhill G, Touza J (2013) Documenting social simulation models: the ODD protocol as a standard. In: Edmonds B, Meyer $\mathrm{R}$ (eds) Simulating social complexity, understanding complex systems. Springer, Berlin, pp 117-133

Grow A, Flache A, Wittek R (2015) An agent-based model of status construction in task focused groups. J Artif Soc Soc Simul 18(2):4

Guerra NG, Williams KR, Sadek S (2011) Understanding bullying and victimization during childhood and adolescence: a mixed methods study. Child Dev 82(1):295-310. https://doi. org/10.1111/j.1467-8624.2010.01556.x

Hamill L (2010) Agent-Based Modelling: The Next 15 Years. J Artif Soc Soc Simul 13(4):7. https://doi.org/10.18564/jasss.1640

Haviland JJ, Malatesta CZ (1981). The development of sex differences in nonverbal signals: fallacies, facts, and fantasies Gender and nonverbal behavior (pp 183-208): Springer

Heise DR (2013) Modeling interactions in small groups. Soc Psychol Quarterly 76(1):52-72. https://doi. org/10.1177/0190272512467654

Hofstede GJ (2013) Theory in social simulation: Status-Power theory, national culture and emergence of the glass ceiling. Paper presented at the AISB 2013 Social.Path, Exeter

Hofstede G, Hofstede GJ, Minkov M (2010) Cultures and Organizations, Software of the Mind, 3rd edn. McGraw Hill, New York

Hofstede GJ, Dignum F, Prada R, Student J, Vanhée L (2015). Gender differences: the role of nature, nurture, social identity and self-organization. In Grimaldo F, Norling E (eds), Multi-AgentBased Systems Workshop (MABS) 2014, LNAI 9002 (pp 72-87): Springer

Humphreys AP, Smith PK (1987). Rough and tumble, friendship, and dominance in schoolchildren: Evidence for continuity and change with age. Child Dev 201-212. https://doi.org/10.2307/1130302

Jarvis P (2007) Monsters, magic and Mr Psycho: a biocultural approach to rough and tumble play in the early years of primary school. Early Years 27(2):171-188. https://doi. org/10.1080/09575140701425324 
Jepperson R, Meyer JW (2011) Multiple levels of analysis and the limitations of methodological individualisms. Sociol Theory 29(1):54-73. https://doi.org/10.1111/j.1467-9558.2010.01387.x

Kang SK, Inzlicht M (2012) Stigma building blocks how instruction and experience teach children about rejection by outgroups. Pers Soc Psychol Bull 38(3):357-369. https://doi. org/10.1177/0146167211426729

Kemper TD (2011) Status, power and ritual interaction; a relational reading of durkheim, goffman and collins. Ashgate, Farnham

Lansu TA, Cillessen AH, Bukowski WM (2013) Implicit and explicit peer evaluation: associations with early adolescents' prosociality, aggression, and bullying. J Res Adolesc. https://doi.org/10.1111/ jora. 12028

Lewis MD (2000) The promise of dynamic systems approaches for an integrated account of human development. Child Dev 71(1):3643. https://doi.org/10.1111/1467-8624.00116

Maccoby EE (2002). Gender and social exchange: a developmental perspective new directions for child and adolescent development (vol 95, pp 87-105): Wiley

Major B (1981). Gender patterns in touching behavior Gender and nonverbal behavior (pp 15-37): Springer

Malatesta CZ, Haviland JM (1982). Learning display rules: The socialization of emotion expression in infancy. Child Dev 991-1003. https://doi.org/10.2307/1129139

Manzo G, Baldassarri D (2014) Heuristics, interactions, and status hierarchies: an agent-based model of deference exchange. Sociol Methods Res. https://doi.org/10.1177/0049124114544225

Martin JL (2009) Formation and stabilization of vertical hierarchies among adolescents: towards a quantitative ethology of dominance among humans. Soc Psychol Quart 72(3):241-264

Martínez-Lozano VS-M, José A, Goudena PP (2011) A crosscultural study of observed conflict between young children. J Cross Cult Psychol 42(6):895-907. https://doi. org/10.1177/0022022110381361

Mascarenhas S, Prada R, Paiva A, Hofstede GJ (2013) Social importance dynamics: a model for culturally-adaptive agents. In Aylett R, Krenn B, Pelachaud C, Shimodaira H (eds), Intelligent virtual agents (vol 8108, pp 325-338): Springer

Moss S, Edmonds B (2005). Towards good social science. J Artif Soc Soc Simul 8(4)

Müller B, Bohn F, Dreßler G, Groeneveld J, Klassert C, Martin R, Schwarz N (2013) Describing human decisions in agentbased models-ODD + D, an extension of the ODD protocol. Environ Model Softw 48:37-48. https://doi.org/10.1016/j. envsoft.2013.06.003

Parke RD, Slaby RG (1983) The development of aggression. Handbook of child psychology 4:547-641

Pellegrini AD (1988) Elementary-school children's rough-and-tumble play and social competence. Dev Psychol 24(6):802. https://doi. org/10.1037/0012-1649.24.6.802

Pellegrini AD, Smith PK (1998) Physical activity play: the nature and function of a neglected aspect of play. Child Dev 69(3):577-598
Ridgeway CL (2011). Framed by gender: how gender inequality persists in the modern world: Oxford University Press

Rodkin P, Farmer T, Pearl R, Van Acker R (2000) Heterogeneity of poplar boys: antisocial and prosocial configurations. Dev Psychol 36:14-24

Rose AJ, Rudolph KD (2006) A review of sex differences in peer relationship processes: potential trade-offs for the Emotional and behavioral development of girls and boys. Psychol Bull 132(1):98-131. https://doi.org/10.1037/0033-2909.132.1.98

Sabater-Mir J, Paolucci M, Conte R (2006). REPutation and ImAGE Among Limited Autonomous Partners'. J Artif Soc Soc Simul 9(2). http://jasss.soc.surrey.ac.uk/9/2/3.html

Sameroff A (2010) A unified theory of development: a dialectic integration of nature and nurture. Child Dev 81(1):6-22. https://doi. org/10.1111/j.1467-8624.2009.01378.x

Scarr S (1993) Biological and cultural diversity: the legacy of Darwin for development. Child Dev 64:1333-1353. https://doi. org/10.1111/j.1467-8624.1993.tb02956.x

Shutts K (2015) Young children's preferences: gender, race, and social status. Child Dev Perspect 9(4):262-266. https://doi.org/10.1111/ cdep. 12154

Thorne B (1993) Gender play: girls and boys in school. Rutgers University Press, New Brunswick

Tremblay RE, Japel C, Perusse D, McDuff P, Boivin M, Zoccolillo M, Montplaisir J (1999) The search for the age of 'onset'of physical aggression: Rousseau and Bandura revisited. Crim Behav Mental Health 9(1):8-23. https://doi.org/10.1002/cbm.288

Turiel E, Wainryb C (2000) Social life in cultures: judgements, conflict, and subversion. Child Dev 71(1):250-256. https://doi. org/10.1111/1467-8624.00140

United-Nations-Development-Programme (2015) Gender inequality index. http://hdr.undp.org/en/content/ table-4-gender-inequality-index

van Geert P (2011) The contribution of complex dynamic systems to development. Child Dev Perspect 5(4):273-278. https://doi. org/10.1111/j.1750-8606.2011.00197.x

Warden D, Mackinnon S (2003) Prosocial children, bullies and victims: an investigation of their sociometric status, empathy and social problem-solving strategies. Br J Dev Psychol 21(3):367-385. https://doi.org/10.1348/026151003322277757

Wilensky U (1999) Netlogo. http://ccl.northwestern.edu/netlogo/

Wilson R (2007) Simulating the effect of social influence on decision-making in small, task-oriented, groups. Journal of Artificial Societies and Social Simulation 10(4). http://jasss.soc.surrey. ac.uk/10/4/4/citation.html

Woods R (2013) Children's moral lives: an ethnographic and psychological approach. Wiley-Blackwell, Chichester

Zimmer-Gembeck MJ, Geiger TC, Crick NR (2005) Relational and physical aggression, prosocial behavior, and peer relations gender moderation and bidirectional associations. J Early Adolesc 25(4):421-452. https://doi.org/10.1177/0272431605279841 